\title{
Stories of Change in Nutrition in Ghana: a focus on stunting and anemia among children under-five years (2009 - 2018)
}

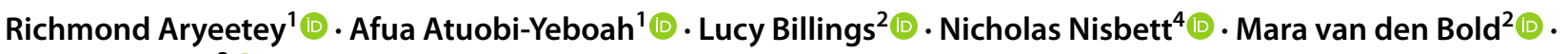 \\ Mariama Toure $^{3}$ (1)
}

Received: 22 December 2020 / Accepted: 17 October 2021 / Published online: 8 November 2021

(c) The Author(s) 2021

\begin{abstract}
The current study aimed to understand why child stunting and anemia (CS\&A) rates declined in Ghana between 2009 and 2018, and which priority policies and programs will further improve nutrition outcomes. Trends and potential drivers of stunting (height-for-age z-score $<-2.0 \mathrm{SD}$ ) and anemia (hemoglobin $<11.0 \mathrm{~g} / \mathrm{dL}$ ), and decomposition analysis of DHS data (2003 to 2014) were conducted. The quantitative evidence was triangulated with Net-Map analysis of nutrition stakeholder relationships and influence, desk review of policies and programs 2009-2019, and in-depth interviews with 25 stakeholders who provided additional insights to explain CS\&A trends. Declines in stunting (29.6\%) and anemia (14.1\%) in children were observed at the national level, but with important subgroup variations. Decomposition analyses identified changes in the household, maternal, and child characteristics (including wealth, use of antenatal services, maternal education, and immunization) as correlates of anemia reduction. Stunting reduction was linked with changes in bed-net utilization, household wealth, and pregnancy care service utilization. Additionally, multiple policies and programs initiated/implemented across multiple sectors were considered potentially relevant to CS\&A reduction over time, including those focused on infant and young child feeding, water and sanitation, social protection, and health care access. Initiation/strengthening of these interventions was stimulated by awareness creation and subsequently increased prioritization of stunting. However, program delivery was limited by deficits in government funding, perceived low priority of child anemia, low implementation capacity and coverage, and weak coherence across sectors. Reduced CS\&A resulted from improved access to services implemented across multiple sectors, albeit limited by implementation scale and capacity. Further reduction in CS\&A requires enhanced multi-sectorally coordinated actions and capacity.
\end{abstract}

Keywords Stories of change $\cdot$ Stunting $\cdot$ Anemia $\cdot$ Drivers $\cdot$ Child $\cdot$ Ghana $\cdot$ Policy $\cdot$ Program

\section{Introduction}

This article belongs to the Topical Collection: Stories of Change in Nutrition: Lessons from Africa and Asia

Guest Editors: Stuart Gillespie, Nicholas Nisbett, Mara van den Bold, Jody Harris

Richmond Aryeetey

raryeetey@ug.edu.gh

Afua Atuobi-Yeboah

afuaay@gmail.com

Lucy Billings

1.billings@cgiar.org

Nicholas Nisbett

n.nisbett@ids.ac.uk

Mara van den Bold

Mara.vandenbold@cgiar.org
There is global interest in reducing child undernutrition, with a particular focus on stunting and anemia (World Health Organization (WHO, 2014). Both outcomes are

\author{
Mariama Toure \\ m.toure@cgiar.org \\ 1 School of Public Health), University of Ghana, Legon, \\ Accra, Ghana \\ 2 International Food Policy Research Institute, Washington, \\ DC, USA \\ 3 International Food Policy Research Institute, Dakar, Senegal \\ 4 Institute of Development Studies, Brighton, UK
}


linked with adverse health and wellbeing, particularly in low-income settings (Black et al., 2013). Stunting impairs immune capacity and cognitive development, increases the risk of morbidity and mortality, adversely affects long-term intellectual performance, and increases the risk of obesity and non-communicable diseases later in life (Black et al., 2008; Black et al., 2013). Anemia also affects children's wellbeing through impaired physical, cognitive, and socioemotional development, resulting in later-onset productivity deficits (Allali et al., 2017).

In Ghana, significant progress has been achieved in reducing undernutrition among young children. Between 2008 and 2018, under-five stunting prevalence declined from 28 to $18 \%$ (Ghana Statistical Service (GSS), Ghana Health Service (GHS), \& ICF International, 2015; Ghana Statistical Service (GSS), Ghana Health Services (GHS), \& ICF Macro, 2009). During the same period, child anemia remained extremely high, with only a marginal decline, from $76 \%$ in 2008 to 66\% in 2014 (Ghana Statistical Service (GSS) et al., 2015; Ghana Statistical Service (GSS) et al., 2009). Reduction in stunting and anemia rates over time are interesting to understand from a decision-making perspective. The difference in magnitude of decline between stunting and anemia is also interesting because it suggests a gap in specific actions for anemia, even though stunting and anemia share many of the same underlying and basic causes. Understanding the basis for these changes, however, is important for learning lessons that will inform better policy and program planning.

In 2011, Ghana signed up with the global Scaling Up Nutrition (SUN) movement with a focus on efforts to address undernutrition among the most vulnerable groups: women of reproductive age, and children (Scaling Up Nutrition Movement (SUN), 2014). Consequently, a multi-stakeholder platform (MSP) was established that spearheaded the finalization of an ongoing process to develop a National Nutrition Policy (NNP). Because the determinants of malnutrition are multi-factorial, the MSP is intended to enhance horizontal coherence (harmonization across relevant agencies) towards achieving agreed objectives (S. Gillespie et al., 2013). Additionally, a range of policies and programs have been implemented, directly or indirectly, to address malnutrition, including a national long-term strategic plan for food and nutrition security for Ghana (Government of Ghana, 2016; National Development Planning Commission (NDPC), 2016), a cash transfer program targeting ultra-poor households, agricultural subsidies, biofortification of selected food crops, and increased investment in school-based services (Government of Ghana (GoG), 2015; Ministry of Food and Agriculture (MoFA), 2010; Ministry of Gender, 2020).

However, it is not known whether these interventions are responsible for the observed decline in stunting and anemia among children; and if so, how these interventions contributed to the decline. Thus, the current study determined the changes in stunting and anemia (2009 to 2018), as well as their drivers, to establish why and how the reduction in CS\&A occurred during this period. In addition, the study identifies challenges and barriers to nutrition policy and program implementation. The study further explores outcomes, priorities, policies, programs, and capacities to consider in planning for the decade following 2018. The study harnessed both secondary and primary data to describe the trends in the national-level nutrition situation over the past decade (2009-2018), as well as to explain the reasons for those trends.

The current study uses the Stories of Change in Nutrition approach, which has been applied elsewhere in Sub-Saharan Africa and Asia, in previous studies (S. Gillespie et al., 2016; Gillespie \& van den Bold, 2017; Nisbett \& Barnett, 2017). Stories of Change is a discovery-based story-telling approach and has been used to holistically explore drivers of change over time in nutrition, in different contexts (Bailey, 2015; S. Gillespie et al., 2016). The current study in Ghana was implemented as part of the Transform Nutrition West Africa (2017 - 2021) initiative that also involved Nigeria, Senegal, and Burkina Faso as focal countries (R. Aryeetey et al., 2020). Transform Nutrition West Africa is a subregional initiative aimed at synthesizing evidence to inform decision-making for better nutrition outcomes in high burden countries (International Food Policy Research Institute (IFPRI), 2021).

\section{Methods}

\subsection{Data collection}

The current study triangulated data gathered using diverse methods including desk review, in-depth interviews, and social network mapping, as well as secondary data from nationally-representative surveys. Documents included in the policy review were retrieved through an online search of government Ministries, Departments, and Agencies' websites. Additional documents were obtained via personal contact (email/telephone requests) with key officials in the relevant agencies. Additional Material 3 lists all identified and reviewed policies and programs included in this study. The desk review was carried out between October 2018 and August 2019.

In-depth interviews (IDIs) of 25 national-level key actors served as validation of desk review (described below) evidence, as well as providing an in-depth understanding of how priorities, plans, events, and opportunities shaped implemented policy and programs. The IDI's were carried out between March and August 2019 using a pretested interview guide (Additional Material 1). Respondents were selected from a shortlist of 35 individuals working with 
diverse agencies including government, United Nations agencies, civil society organizations, donor organizations, and academia. This shortlist was generated based on suggestions from a national stakeholder consultation in 2018, that provided input for designing the study as well as how and who to speak with as part of the IDI. All included respondents were operating at the national level, except four regional participants from the Ghana Health Service (GHS); regional respondents were included to elicit their unique sub-national perspectives on policy and program implementation across. All interviews were audio-recorded.

The Net-Map technique for stakeholder mapping was utilized to describe the interactions across stakeholders working to address child stunting and anemia in Ghana (Schiffer $\&$ Waale, 2008). A pre-tested interview guide (Additional Material 2) was used to interview a stakeholder group of 13 respondents, out of 20 who were invited to participate. (Schiffer \& Hauck, 2010; Schiffer \& Waale, 2008). The interview guide was adapted from a previous project on breastfeeding scale-up in Ghana. Briefly, interview participants were given an orientation on the subject of the interview using a conceptual framework of the causal and programmatic linkages between CS\&A and their respective hypothesized drivers (United Nations Children's Fund, 1998). Respondents were then guided to list actors involved in CS\&A policy and programs in Ghana. Respondents then identified types of linkages between actors, while categorizing the linkages as either formal command, funding or technical assistance, or advocacy links. Formal command links refer to formal oversight of one actor over another. Technical assistance links depict relationships based on knowledge or skills transfer. Advocacy links refer to relationships where one actor targets the other with actions aimed to influence change. Finally, actors' relative influence (RI) was determined using a stack of checkers. Most influential actors were assigned five checker pieces and the least influential, one piece. Actors with no checkers assigned indicated either no influence or unknown influence. During the interview, respondents discussed their opinions regarding the list of actors, actor linkages, and their relative influence. All interviews were audio-recorded, and maps were photographed. The Net-map interview was carried out in November 2018. The study was approved by the Ethical Review community of the Ghana Health Service (GHS-ERC008/04/18).

\subsection{Analysis}

\subsubsection{Synthesis of secondary data}

A combination of qualitative and quantitative techniques was applied to secondary and primary data collected and analyzed as described in Gillespie et al., 2017 (see Table 1) (Gillespie \& van den Bold, 2017). For the policy review, a data extraction tool, in the form of an MS Excel spreadsheet, was used. This tool enabled identification of relevant information across the documents necessary to answer questions regarding which interventions had been planned/ implemented to address child stunting and anemia when the documents were published. The tool was also used to extract information on the scope of the policy or program during the review period (2009-2018).

A temporal map of changes in CS\&A prevalence, as well as changes in potential drivers based on the UNICEF Malnutrition Framework (United Nations Children's Fund, 1998), was constructed using reports of the nationally representative surveys (DHS and Multiple Indicator Cluster Survey (MICS)) implemented between 2003 and 2017 in Ghana (Ghana Statistical Service (GSS) et al., 2015; Ghana Statistical Service (GSS) et al., 2009; Ghana Statistical Service (GSS), Noguchi Memorial Institute for Medical Research (NMIMR), \& Inc, 2004). Additional data was obtained from program reports (FAO, IFAD, \& WFP, 2015; Food and Agriculture Organisation (FAO), 2019, International Fund for Agricultural Development (IFAD), United Nations Children's Fund (UNICEF), World Food Programme (WFP, \& World Health Organization (WHO), 2019; Ghana Statistical Service (GSS), Ghana Health Service (GHS), \& ICF, 2018; Ghana Statistical Service (GSS), Ghana Health Services (GHS), \& Macro Inc, 2007; Service, 2013) across multiple sectors to demonstrate changes in potential drivers of child stunting and anemia (United Nations Children's Fund, 1998). Program data complemented evidence from existing survey reports. The temporal map analysis was carried out between May and October 2018.

DHS data were further subjected to decomposition analyses (Gillespie \& van den Bold, 2017; Headey et al., 2017) to identify factors associated with temporal changes in CS\&A. The factors included were based on the UNICEF malnutrition framework (United Nations Children's Fund, 1998). The analysis included a range of nutrition-sensitive explanatory variables at the community and household levels including bed-net availability, residence (rural versus urban), access to improved water, access to an improved toilet, assets, number of children, births interval, and childbirth in a health facility. Maternal-level factors included age, weight, height, school attendance, high school education, and antenatal care (ANC) during pregnancy. Child-level drivers of CS\&A in the analysis included both nutrition-specific (diet diversity, Vitamin A supplementation, vaccination status, diarrhoea, acute respiratory infection) and nutrition-sensitive (bed-net use, age, and sex) factors. The outcome variables in this study were stunting and anemia among children $<60$ months. To test the robustness of the results, sensitivity analyses were performed using height-for-age z-score (HAZ) as a substitute variable for stunting. Similarly, hemoglobin concentration was exchanged for anemia in sensitivity analyses. The 


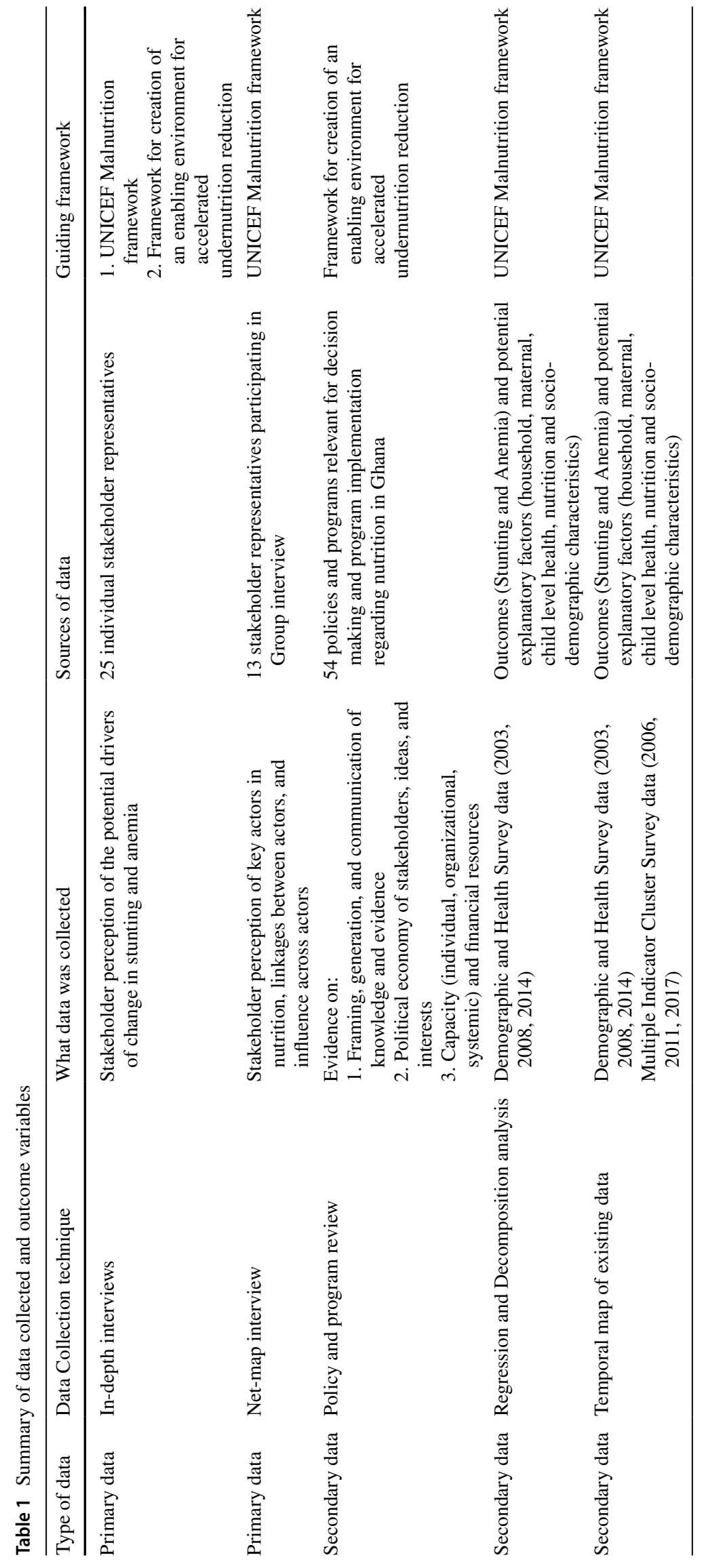


decomposition analyses were applied to available DHS data (2003, 2008, and 2014), to determine the change in linear growth and anemia in children between 2003 and 2014. The decomposition analyses were carried out between May and November 2018.

\subsubsection{Synthesis of primary data}

Qualitative analyses were performed on extracts from existing reports, policies, and programs; IDI transcripts; and stakeholder social-network mapping data and transcripts. The desk review analysis focussed on policies and programs targeting young children $<60$ months, across multiple government agencies, and included both nutrition-specific and nutrition-sensitive sectors. Some policies and programs were included because of their potential linkage with child stunting and anemia, although they were not designed to address CS\&A.

All IDI audio recordings were transcribed verbatim by trained transcribers who were not involved in the data collection. Transcripts were reviewed to ensure the quality of the transcripts and revisions were made as appropriate. The analyses were guided by the framework by Gillespie et al.,
(2013) indicated in Fig. 1, for coding of the text and development/finalization of themes. A thematic content analysis including both an a priori code generation (Additional material 4) and an open coding approach of transcripts were used. Initially, three of the transcripts (selected randomly), were read carefully and used to revise the a priori coding tree. Thereafter, coding was completed independently by two research assistants, based on the revised a priori codes, using a text analysis software, NVIVO version 12 (QSR International, Melbourne, Australia). Discrepancies in the coding were addressed through discussion and mutual agreement.

Data from the Net-map (including the photographs, notes, and transcripts), on the list of actors (using actor identification codes), links between actors, and RI were entered into Microsoft Excel (as two separate sheets: 1. list of individual actors, and 2. list of links connecting all actors). Actor identification codes and actor categories (the broad sectors that actors belong to) were recoded for consistency across the link list and the actor list. The two excel sheets were imported into Gephi (version 0.9.2), a social network analysis software. All analyses (statistics, filtering, network image generation, and visualization) and image capturing were done in the overview and preview features of Gephi.
Fig. 1 Framework for creating an enabling environment for accelerated undernutrition reduction

\author{
Framing, generation, and communication of knowledge and evidence \\ Issues and challenges to creation and sustaining of momentum \\ Framing and narratives \\ Evidence of outcomes and benefits \\ What works and how well do nutrition interventions work relative to others? \\ Advocacy to increase priority (civil society) \\ Evidence of coverage, scale and quality \\ Issues and challenges to conversion of momentum into results \\ Implementation research (what works, why, and how?) \\ Programme evaluation (impact pathways) \\ Generation of demand for evidence of effectiveness
}

Political economy of stakeholders, ideas, and interests

Issues and challenges to creation and sustaining of momentum

Incentivizing and delivering of horizontal coherence (multisectoral coordination)

Development of accountability to citizens

Enabling and incentivizing of positive contributions from the private sector

Issues and challenges to conversion of momentum into results

Delivery of vertical coherence

The role of civil society and the private sector in delivery

Capacity (individual, organizational, systemic) and financial resources

Issues and challenges to creation and sustaining of momentum

Leadership and championing

Systemic and strategic capacity

Making the case for additional resource mobilization

Issues and challenges to conversion of momentum into results

Delivery and operational capacity

New forms of resource mobilization

Prioritization and sequencing of nutrition action

$\underline{\text { Implementation and scale-up }}$ 
Overall and link-specific network statistics (weighted average degrees, network diameter, graph density, modularity, and connectedness components) were computed to determine network characteristics. Further, the average clustering coefficient and eigenvector centrality were calculated (Box 1).

The network visualization images were developed by weighting the actor nodes using relative influence of each actorI. Actor categories were differentiated by color. The Yifan $\mathrm{Hu}$ algorithm was used to visualize network images $(\mathrm{Hu}, 2005)$. Actor influence data was transformed from a scale of 0 to 5 to between 0 and 1 . The findings of the study were validated by stakeholders from multiple sectors relevant to nutrition and health (civil society, government agencies, united nations agencies, donors, academia, and research) during a validation workshop in January 2020.

\subsubsection{Triangulation of data}

Together, analysis of the IDIs and policy and program reviews focused on identifying reasons for commitment to addressing child stunting and anemia as well as the strengths and weaknesses characterizing horizontal and vertical coherence in policy and program implementation. Vertical coherence refers to the harmonization of policies and actions across levels and hierarchies of governance (from the national level down to district or community levels). The study also identified weaknesses, barriers, and challenges in policy and program implementation, and reasons for such weaknesses. Additional Material 5 shows illustrative quotations from the IDIs.

The analysis of temporal trends describes and compares the change in CS\&A between 2009 and 2018, as well as the potential nutrition-specific (diet- and disease-related) and nutrition-sensitive (non-dietary factors including hygiene, care, and food security) drivers of stunting and anemia during this period (Khalid et al., 2019). In addition to nationallevel trends, regional-level.

data on CS\&A were compared over time to identify inequalities in outcomes over time and across regions.

\section{Box 1: Description of network description statistics/indicators}

Network/graph density: Measurement of how close the network is to complete. A complete graph has all possible edges, and density is equal to 1

Network diameter: The longest graph distance between any two actors in the network (i.e., how far apart are the two most distant actors)

Average degree: An average of the degree centrality

Degree Centrality: The number of links/edges connected to an actor e.g., the actors with the most connections

Betweenness centrality: Measurement of how often an actor appears on the shortest paths between actors in the network
Box 1: Description of network description statistics/indicators

Connected components: Determines the number of connected components in the network. A directed graph detects strongly and weekly connected components

Clustering coefficient: Indicates how actors are embedded in their neighborhood. The average gives an overall indication of the clustering in the network

Modularity: Community detection algorithm

Average path length: The average distance between all pairs of actors

\section{Results}

\subsection{Outcomes and drivers}

\subsubsection{Trends in stunting and anemia}

DHS and MICS conducted between 2008 and 2017 show a consistent decline in child undernutrition among young children. This finding is supported by the trend analysis which shows that between 2003 and 2014, stunting declined impressively by $48 \%$. The observed declines were particularly outstanding for stunting (from 28 to 18\%) at the national level (Fig. 2) (Ghana Statistical Service, 2012; Ghana Statistical Service (GSS), 2011; Ghana Statistical Service (GSS) et al., 2015; Ghana Statistical Service (GSS) et al., 2009; Ghana Statistical Service (GSS) et al., 2004; Ghana Statistical Service (GSS). 2018). Despite the general decline, wide disparities in child growth outcomes were observed across administrative regions in Ghana. For example, Greater Accra Region had the lowest stunting rate in 2014 (10.4\%), while in the Northern region, the rate was $33.1 \%$ (Table 2). Thus, between 2008 and 2014, stunting declined by more than $25 \%$ in Greater Accra Region but increased by $2 \%$ in Northern Region. Generally, stunting rates were higher among males, in rural areas, in homes with fewer assets, and lower maternal educational attainment (Ghana Statistical Service (GSS) et al., 2015; Ghana Statistical Service (GSS) et al., 2009).

Although there had been a marginal decline of child anemia from $78 \%$ in 2008 to $67 \%$ in 2014 (Ghana Statistical Service (GSS) et al., 2015; Ghana Statistical Service (GSS) et al., 2009) the rates remained well above the WHO's threshold for a serious public health problem (Fig. 2). Unlike the situation with growth indicators, anemia rates are high in every region, ranging between 54\% in Ashanti Region and $82 \%$ in the Northern region in 2014; the temporal differences across regions were not different (Table 2). Generally, anemia rates were higher in rural areas, in Northern Ghana, and in homes with fewer assets, or low maternal educational attainment. 
Fig. 2 Trends in stunting and anemia among young children (6-59mo) in Ghana
A. Stunting among young children (6-59mo) (2003-2017)

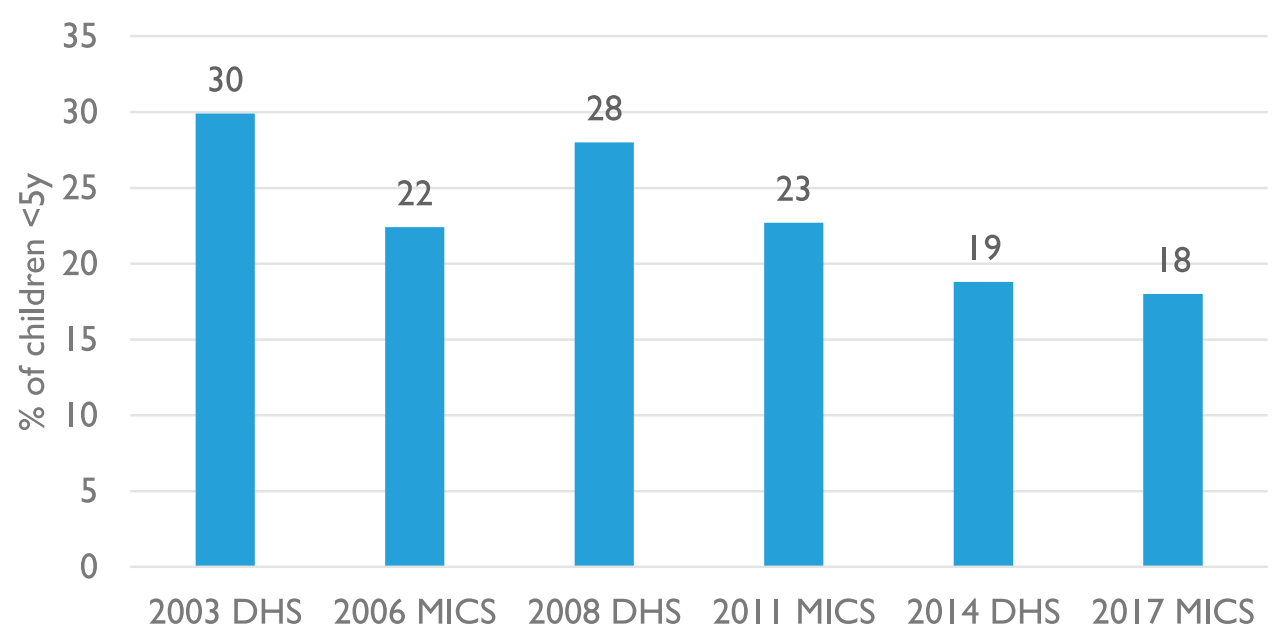

B. Anemia among young children (6-59 mo) (2003-2014)

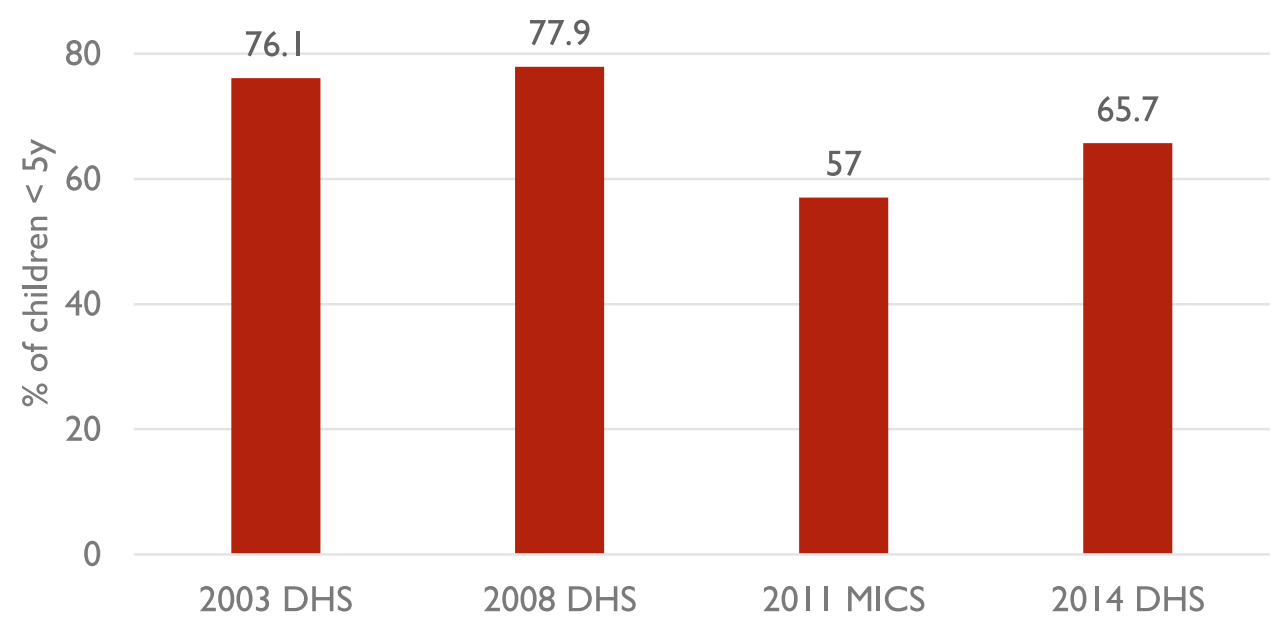

\begin{tabular}{|c|c|c|c|c|c|c|c|c|c|c|c|c|}
\hline & \multicolumn{3}{|c|}{ Stunting } & \multicolumn{3}{|c|}{ Underweight } & \multicolumn{3}{|c|}{ Wasting } & \multicolumn{3}{|c|}{ Anemia } \\
\hline & 2003 & 2008 & 2014 & 2003 & 2008 & 2014 & 2003 & 2008 & 2014 & 2003 & 2008 & 2014 \\
\hline Greater Accra & 13.9 & 14.2 & 10.4 & 11.5 & 6.5 & 3.7 & 7.2 & 5.9 & 8.7 & 61.3 & 62.1 & 59.6 \\
\hline Ashanti & 29.1 & 26.5 & 16.1 & 20.8 & 12.1 & 3.5 & 6.7 & 9.2 & 9.4 & 79.0 & 77.9 & 53.7 \\
\hline Brong-Ahafo & 29.4 & 25.2 & 17.2 & 20.4 & 13.5 & 4.5 & 5.7 & 5.4 & 5.9 & 74.9 & 78.3 & 62.5 \\
\hline Eastern & 27.4 & 37.9 & 17 & 17.3 & 8.7 & 3.2 & 6.2 & 6.4 & 7.9 & 74.4 & 73.1 & 66.1 \\
\hline Volta & 23.3 & 26.8 & 19.3 & 25.7 & 13.6 & 2.5 & 13.9 & 5.2 & 10.5 & 72.7 & 78.7 & 69.9 \\
\hline Central & 31.6 & 33.7 & 22 & 22.0 & 17.2 & 7.7 & 3.0 & 12.0 & 13.9 & 76.8 & 84.5 & 70.2 \\
\hline Western & 28.4 & 27.0 & 17.7 & 16.5 & 10.3 & 3.9 & 5.3 & 5.6 & 10.6 & 80.4 & 80.4 & 64.6 \\
\hline Upper East & 31.7 & 36.0 & 14.4 & 32.4 & 27.0 & 9.4 & 12.9 & 10.8 & 10.8 & 79.1 & 88.5 & 73.8 \\
\hline Upper West & 34.1 & 24.6 & 22.2 & 25.9 & 13.1 & 4.4 & 11.0 & 13.9 & 13.5 & 78.3 & 88.2 & 73.8 \\
\hline Northern & 48.8 & 32.4 & 33.1 & 35.5 & 21.8 & 6.3 & 6.6 & 12.9 & 20.0 & 82.5 & 81.4 & 82.1 \\
\hline National & 29.9 & 28.0 & 18.8 & 22.1 & 13.3 & 11.0 & 7.1 & 8.5 & 4.7 & 76.1 & 77.9 & 65.7 \\
\hline
\end{tabular}




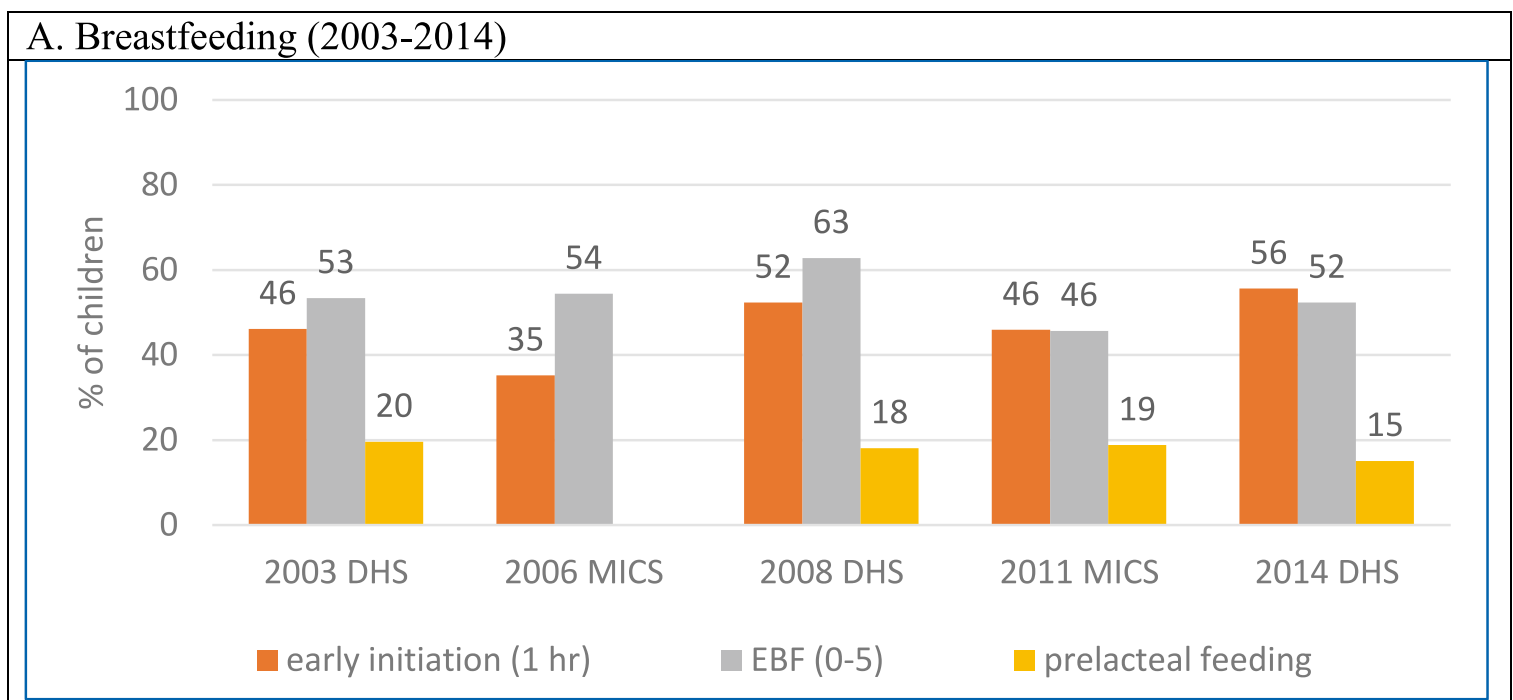

B. Complementary feeding (2008-2017)

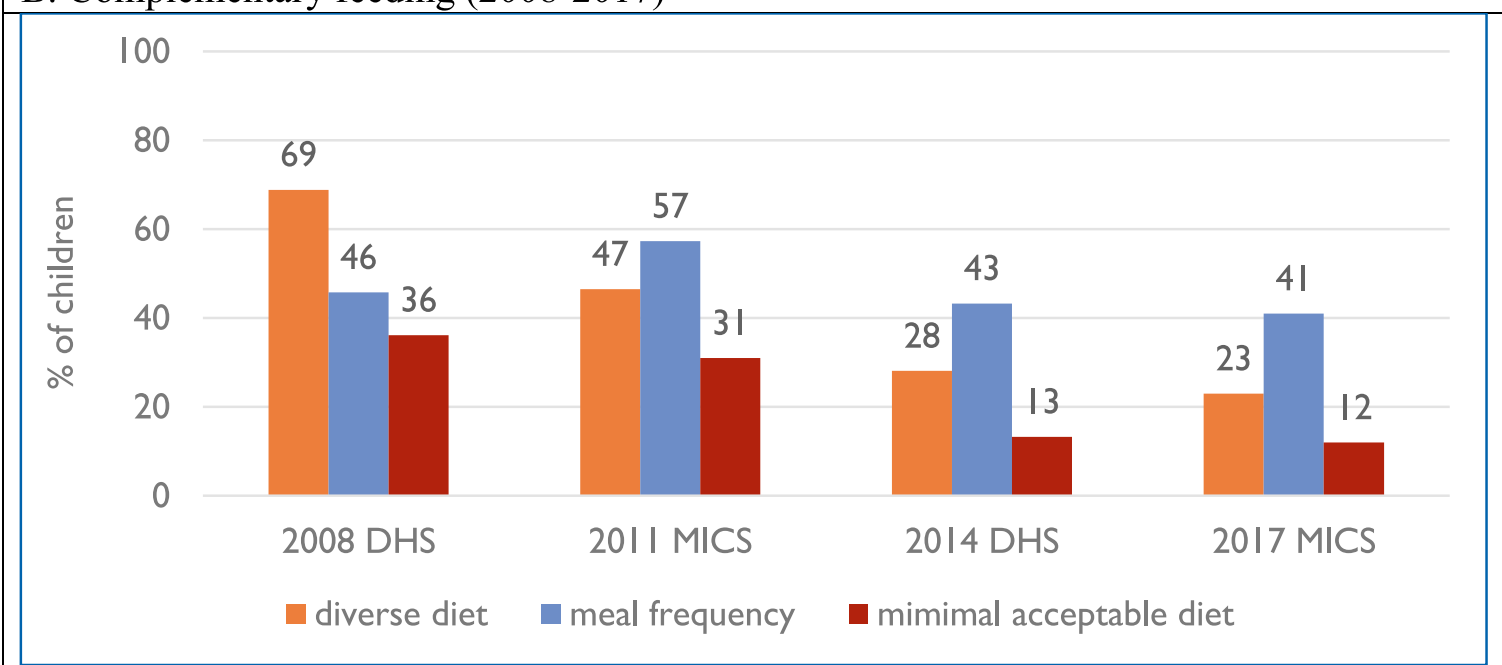

C. Household water and sanitation (2003-2017)

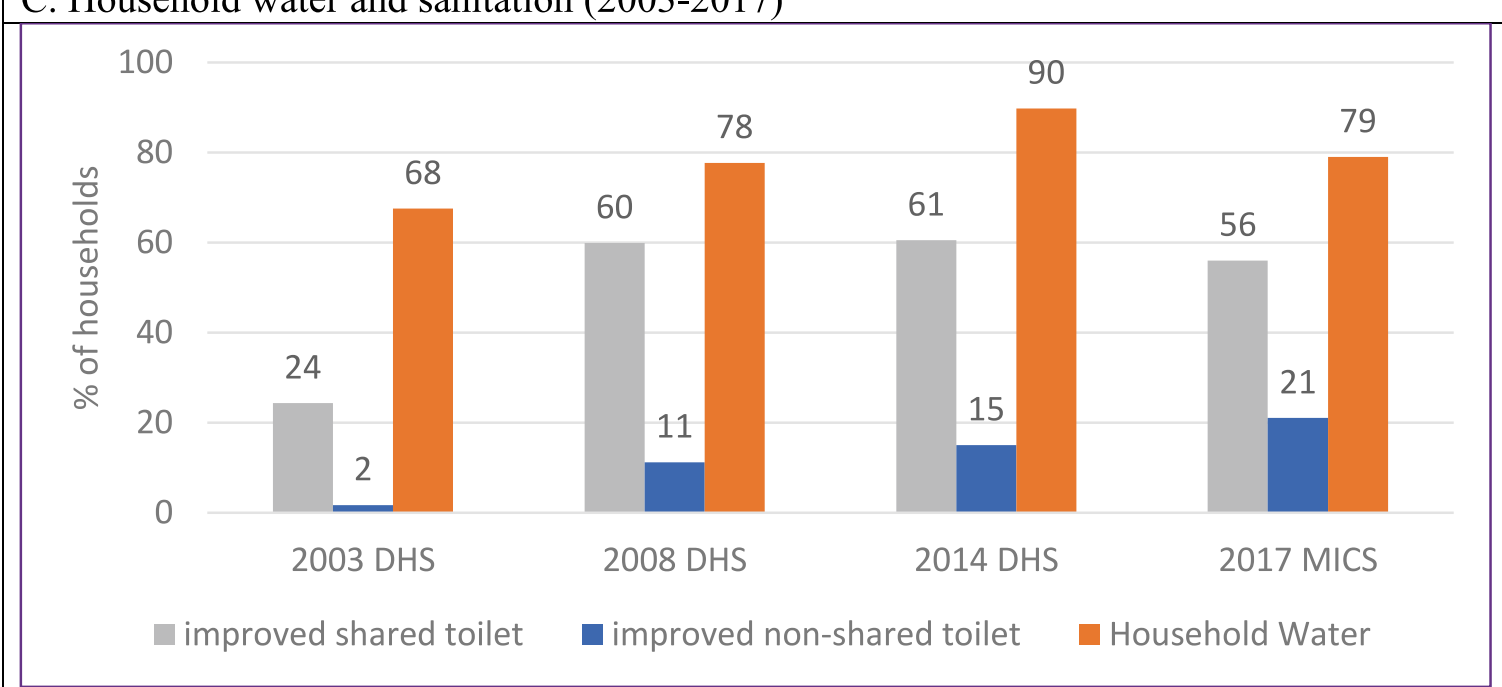

DHS= Demographic and Health Survey; MICS= Multiple Indicator Cluster Survey; EBF= Exclusive Breastfeeding

Fig. 3 Trends in drivers of child Stunting and Anemia in Ghana (2003-2017) 


\subsection{Trends in immediate drivers of child stunting and anemia}

Between 2009 and 2018, there was no clear change in the pattern of child breastfeeding practices (Fig. 3). Although almost all children were breastfed, the prevalence of early initiation of breastfeeding (within one hour of delivery) declined marginally between 2008 and 2011 from 52 to $46 \%$ but increased to $52 \%$ in 2017. Prevalence of exclusive breastfeeding reached a peak of $63 \%$ in 2008 , and thereafter, declined to $43 \%$ in 2017 , the lowest in two decades. During the same period, there was a consistent decline in complementary feeding performance. Among children, 6-23 months, the minimum diverse diet rate (i.e., at least 3-4 food groups/day, depending on age) was $23 \%$ and minimum meal frequency was $41 \%$ in 2017 . Consequently, the minimum acceptable diet rate, which combines diet diversity and meal frequency rates, has declined consistently in the last decade (from $36.2 \%$ in 2008 to $12 \%$ in 2017) (Fig. 3).

Data on uptake of health system services demonstrates general sub-optimal performance and inconsistent trends. For example, the 2014 DHS shows that only two-thirds of young children under-5 years and postpartum women were receiving vitamin A supplements; this represents only a marginal improvement from 2008. The rate of ownership of insecticide-treated bed-nets, however, increased from $42 \%$ in 2008 to $68 \%$ in 2014. Despite this increase, only about a third of young children slept under these treated nets in 2014. Similarly, only about a third of young children received deworming medication in the past six months in 2014. Also, full vaccination against infectious diseases of childhood was achieved among about $80 \%$ of young children in 2008 but decreased slightly to $77 \%$ in 2014 . The rate of
ANC attendance also increased (from $78 \%$ in 2008 to $87 \%$ in 2014).

\subsection{Trends in underlying drivers of child stunting and anemia}

Changes in the indicators of water, sanitation, and hygiene (WASH) over time also did not follow a consistent change pattern. Access to potable household water was highest among the three WASH indicators reported in the surveys between 2008 and 2014. At the national level, access to improved water at the household level increased from $78 \%$ in 2008 to $90 \%$ in 2014 but declined slightly to $80 \%$ in 2017. Only about half of households used an improved toilet in 2014; this estimate is a slight decline from $60 \%$ in 2008. The practice of handwashing with running water and soap has increased consistently since 2008 (Fig. 3). There was increased economic access to health care through the health insurance system. Enrolment at the national level in the national/district health insurance scheme among women of reproductive age improved to $62.0 \%$ in 2014 , compared to $38.8 \%$ in 2008 .

\subsection{Quantitative correlates of stunting and anemia}

Ten correlates were linked to changes in child stunting and eight for child anemia between 2003 and 2014 (Table 3). Stunting reduction was correlated with changes in the prevalence of household bed-net ownership, household assets, and attending ANC at least four times during pregnancy of the index child (Fig. 4). Further, changes in the number of children in the household, years of maternal education, birth intervals, and maternal height were associated with a marginal reduction
Table 3 Estimate of changes in drivers of stunting and anemia in Ghana

\begin{tabular}{llllll}
\hline Drivers of stunting or anemia & 2003 & 2008 & 2014 & $\begin{array}{l}\text { Change } \\
(2003-2014)\end{array}$ & \% of Change \\
\hline Asset Index, 1-10 & 2.61 & 3.15 & 4.13 & 1.52 & 58 \\
Maternal education (years) & 4.18 & 4.53 & 5.02 & 0.85 & 20 \\
Paternal education (years) & 6.47 & 6.86 & 6.98 & 0.51 & 8 \\
4 prenatal visits or more (\%) & 70 & 79 & 87 & 17 & 24 \\
Fully immunized (\%) & 33 & 49 & 53 & 20 & 61 \\
Born in medical facility (\%) & 41 & 54 & 69 & 28 & 67 \\
Open defecation (\%) & 32 & 29 & 26 & -6 & -17 \\
Improved water source (\%) & 40 & 76 & 79 & 39 & 96 \\
Prevalence of diarrhea (\%) & 17 & 22 & 13 & -4 & -24 \\
Improved toilet (\%) & 69 & 71 & 75 & 6 & 8.7 \\
Number of children & 4.57 & 4.31 & 4.25 & -0.32 & -7 \\
Birth interval (years) & 3.76 & 3.84 & 3.98 & 0.22 & 6 \\
Maternal underweight (\%) & 8.8 & 7.2 & 4.6 & -4.2 & -48 \\
Maternal height (cm) & 158.92 & 158.78 & 158.91 & -0.01 & 0 \\
Presence of bednet in household (\%) & 25 & 73 & 81 & 57 & 231 \\
\hline
\end{tabular}


$100 \%$

$80 \%$

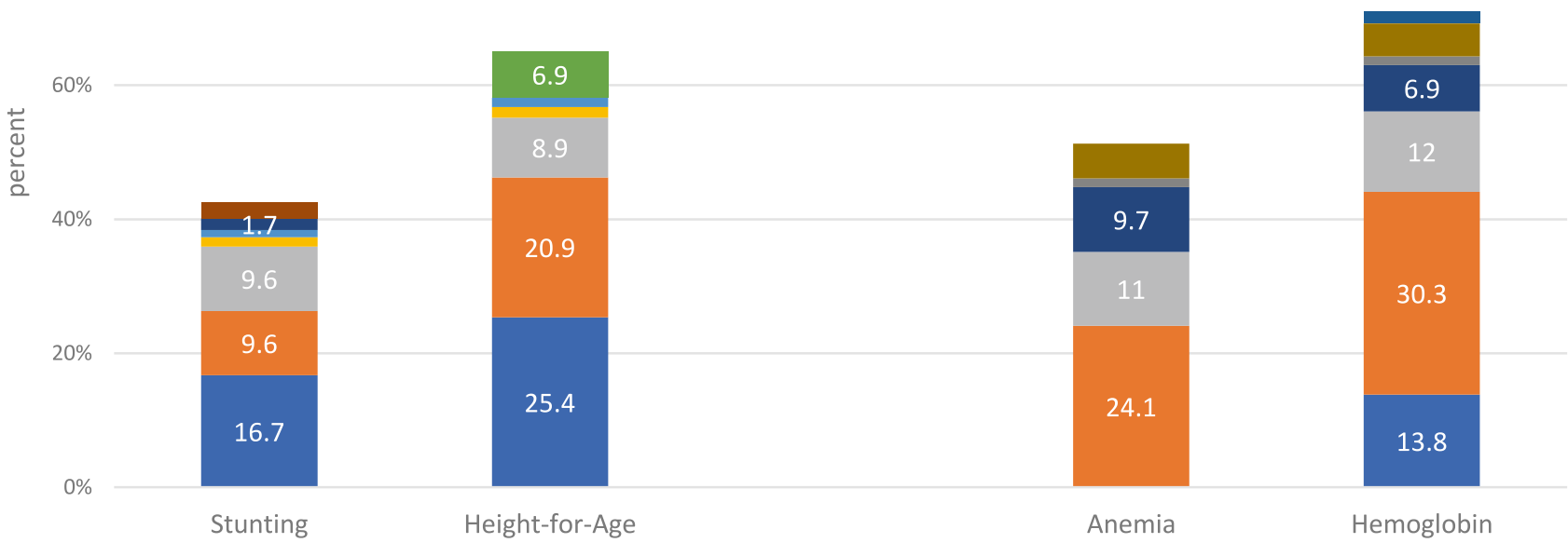

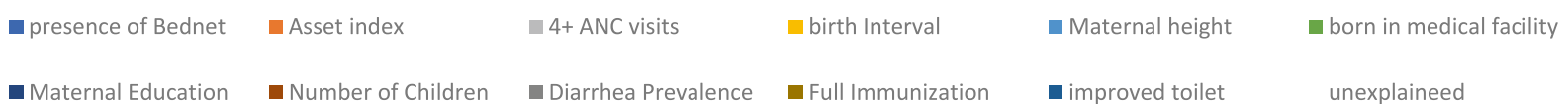

Fig. 4 Estimated contribution of selected factors to changes in stunting and anemia outcomes in Ghana (2003-2014)

of stunting. Altogether, changes in these factors explained less than half of the total reduction in stunting between 2003 and 2014. In sensitivity analysis using HAZ as the outcome, $65 \%$ of changes in HAZ were associated with the same factors identified when stunting was used as the outcome variable.

Anemia reduction between 2003 and 2014 was correlated, primarily to changes in household assets, ANC attendance for at least for times during pregnancy of the index child, maternal years of education, and full immunization of the child (Fig. 4). In addition, a reduced prevalence of diarrhea was associated with a marginal change in anemia. Altogether, changes in these factors were linked with about half of the reduction in stunting, during the period between 2003 and 2014. Sensitivity analysis using Hemoglobin as the outcome variable indicated that $71 \%$ of the change in hemoglobin was linked with these variables. In the hemoglobin analysis, the important correlates of increased average hemoglobin concentration were asset index, household bed-net, ANC attendance for at least for times during pregnancy of index child, maternal years of education, and full immunization of index child (Fig. 4).

\subsection{Ideas, framing and prioritization of stunting and anemia}

\subsubsection{Advocacy and Awareness Creation on child stunting and anemia}

IDI data analysis indicated that during the past decade, nutrition champions (influential individuals) contributed to the creation of awareness of malnutrition as well as policy processes to address child malnutrition. The champions who played advocacy roles included political office holders, and institutional administrative leaders (Scaling Up Nutrition Movement (SUN), 2014). In the Net-map interviews and IDIs, respondents indicated that community mobilization activities that contributed to the identification, formation, and training of health committees were important advocacy mechanisms that contributed to addressing stunting and anemia. The Net-map interviews further showed that the stakeholders who are considered as most influential in the stunting and anemia network (including UNICEF, WHO, 
GHS and the University of Ghana, and Ministry of Health) were actively involved in advocacy activities for both stunting and anemia, but more prominently for stunting.

Awareness creation for nutrition was supported by evidence on the links between undernutrition and child mortality. IDI participants indicated that there is now a better understanding of nutrition by District Health Management teams. Participation by key stakeholders in international events and conferences such as the second International Conference on Nutrition held in Rome in 2016, the declaration of the Decade of Nutrition in 2016 by the United Nations, and the global gathering meetings of the SUN movement provided an opportunity for awareness creation about undernutrition. Also, in 2012, UNICEF hosted a West Africa sub-regional stunting reduction workshop in Accra that brought together key stakeholders to share ideas on how to address stunting. This event was considered by some IDI participants as an important stimulus for shifting attention towards efforts to address stunting in Ghana and using a multi-sectoral approach.

A key player in the national advocacy effort was the Ghana Coalition of Civil Society Organisations for Scaling Up Nutrition (GHACSSUN), a civil society organization initiated in response to Ghana becoming a part of the SUN (Scaling Up Nutrition Movement Secretariat (SUN), 2015). The actions of GHACSSUN to prioritize nutrition were targeted at decision-makers to elicit increased government funding for nutrition actions, as well as elevate the profile of nutrition in the government's development agenda (Government of Ghana, 2010).

Evidence from the IDI and desk review also indicated the role of awareness creation among the general population to stunting and anemia reduction in Ghana. Two interventions focused on awareness creation were identified as most relevant. First is behavior change communication targeting mothers and other caregivers of young children through the USAID-funded Goodlife campaign implemented between 2009 and 2019 (Ghana Health Service (GHS), United States Agency for International Aid (USAID), Communicate for Health, \& United Nations Children's Fund (UNICEF), 2019; United states Agency for International Aid (USAID), 2020). The GoodLife campaign promoted messages that linked with both stunting and anemia including IYCF; malaria prevention and control; WASH; and family planning and maternity care. These messages were delivered via multiple channels (including social media, electronic media, print media) as well as through interpersonal communication and counseling, as part of routine health service delivery. In addition to these, the campaign created job aids for use by health workers to facilitate communication of the messages.

In the desk review, there was evidence of earlier advocacy actions, including promotion of fortified foods by the National Fortification Alliance in 2008 (Nyumuah et al.,
2012; Strengthening Partnerships Results and Innovations in Nutrition Globally (SPRING). \& Ghana Health Service (GHS), 2016), using a combination of television, radio and print messages, and training of media practitioners on how to communicate the message on food fortification. The IDI participants attributed stunting reduction to increased awareness of child undernutrition among key decision-makers, as a result of these advocacy interventions.

\subsubsection{Prioritization of stunting and anemia}

Most stakeholders interviewed were aware of stunting and considered it an important nutrition issue that needs to be addressed due to its linkage with child health, mortality, school performance, and economic productivity. This high level of awareness of stunting was attributed to the availability of evidence on stunting prevalence through nationally representative surveys. Desk review and IDI evidence further showed that stunting had been prioritized, based on different kinds of evidence. In addition to the survey reports of the prevalence of stunting, reference was made to the USAID-supported PROFILES analysis which estimated that between 2011 and 2020, Ghana will lose 3.5 billion dollars to stunting-related decreased worker productivity if no interventions were implemented (Ghana Health Service (GHS) \& United states Agency for International Aid (USAID), 2011). More recently, The Cost of Hunger in Africa-Ghana (COHA) also reported in 2016 that almost a quarter of child deaths (between 2008 and 2012) was linked directly with undernutrition (National Development Planning Commission (NDPC), 2016). Further, $10 \%$ of all cases of repetition of children in school, was linked to stunting, which can result in an economic loss of US\$8.4 million. The total annual loss of productivity due to stunting was estimated at US\$349 million (equivalent to $0.86 \%$ of Gross Domestic Product). The total cost of undernutrition among young children was estimated at US $\$ 2.6$ billion (6.4\% of GDP). Regarding iron deficiency anemia, potential economic losses were estimated to be about US $\$ 1.3$ billion (Ghana Health Service (GHS) \& United states Agency for International Aid (USAID), 2011).

In the GHS, stunting was mainstreamed into the National Health Sector Strategic Plan of Work (Ministry of Health $(\mathrm{MoH}), 2014)$. Priority public health services such as infection prevention and control and IYCF were included in GHS programs such as pregnancy care, neonatal health, and early child health services as part of actions to address child stunting (Ministry of Health (MoH), 2007b, 2007c). Within the GHS, actions that were considered by stakeholders as important for a reduction in stunting included routine reviews of health programs that are implemented at all levels. These reviews are implemented at national, regional, and district levels. Stunting reduction has been particularly prioritized as a key issue in these reviews during the past decade. In 
addition, there were deliberate efforts to provide supportive supervision to lower-level institutions to address deficits in program implementation. More recently, the Ghana Health Service has been convening Zonal reviews in which regions are paired to enable cross-regional interaction and peersupport that motivates the achievement of outcomes.

IDI participants believed that although child anemia control was included as part of health service interventions, it was not prioritized. Instead, the focus was on the control of maternal anemia. The motivation for addressing maternal anemia was to reduce pregnancy- and delivery-related morbidity and mortality among women. Stakeholders were not convinced that specific actions were implemented to address child anemia.

\subsection{Implementation arrangements}

\subsubsection{Policy and program arrangements to address child stunting and anemia}

Evidence from the desk review provides a description and context of policies and programs implemented between 2009 and 2018. Two main documents constituted the flagship policies to address child malnutrition in Ghana during this period. Imagine Ghana Free of Malnutrition was the operational government policy for nutrition between 2005 and 2011, focused on addressing both stunting and anemia. In 2010, the World Bank, in collaboration with GHS commissioned the drafting of a National Nutrition Policy (NNP). The finalization of the NNP was delayed for several years until it was eventually endorsed by the Ministry of Health in 2016 and is currently the flagship policy framework for nutrition programming in Ghana (Government of Ghana, 2016). However, a draft version of the NNP was available for use from 2013. Stakeholders in the IDI indicated that for the first time, the NNP positioned malnutrition as a dual issue of health and development, a departure from previous health-focused nutrition policies (Ghartey, 2010). This repositioning allowed other stakeholders who are typically not involved in nutrition to identify potential contributions towards addressing child malnutrition. Many interview participants indicated that the NNP served as an important driver of nutrition action, especially at the sub-national level. One of the ways in which policy drove change was its incorporation in the health sector strategic plan regarding nutrition actions. A strategic plan for implementation of the policy was expected to be developed. However, this has not been accomplished.

In addition to the above, other complementary policies and programs to address stunting and anemia among children were identified (Additional Material 3). Many of the identified policies and programs, especially those in the health sector, referenced the need to address stunting and anemia among children. About half of the policies (52.8\%) originated from the health sector and were designed primarily to address infectious diseases (including Malaria, and Neglected Tropical Diseases) (Ghana Health Service (GHS), 2013; Ghana Health Service (GHS)/National Malaria Control Program (NMCP), 2017), dietary interventions (including IYCF, micronutrient supplementation, food fortification, biofortification, food security (Ministry of Food and Agriculture (MoFA), 2007, 2010), and family planning and safe motherhood (including birth spacing, neonatal and early child care, antenatal and postnatal care) (Ghana Health Service (GHS), 2013, 2014; Ghana Health Service (GHS)/ National Malaria Control Program (NMCP), 2017). Policies and strategies from nutrition-sensitive sectors included policies for WASH (including community-led total sanitation, elimination of open defecation, provision of potable water, personal hygiene practices), and social protection strategies (including cash grants, school meals program) (Government of Ghana (GoG), 2005, 2010a, 2010b; Ministry of Gender, 2020).

\subsection{Types and coverage of nutrition-specific interventions}

Implementation of a range of nutrition-specific interventions (interventions that address the immediate causes of malnutrition) was considered important for child stunting and anemia outcomes. Particularly, child feeding interventions such as the Baby-Friendly Hospitals Initiative, community IYCF, Essential Nutrition Actions, and fortification of foods for children and women of reproductive age (e.g., Obaasima Seal). Regarding IYCF, stakeholders referred to advocacy, counseling, and education of the general public on what and how to feed young children. In addition, new interventions were started during this period that actively engaged communities in the prevention and control of malnutrition among children. For example, the Communitybased Management of Acute Malnutrition is an example of a new intervention that was piloted in one region in 2010 and eventually scaled up throughout the country. Child Growth Monitoring and Promotion (GMP) at the community level was also linked with reduced stunting. The Launch of a new mother-child health card as part of the GMP was also identified as a useful contribution to stunting and anemia control.

However, there was a perception that the diets of children remain suboptimal in terms of the quality of foods given as well as the feeding practices. This perception is consistent with the findings from surveys which showed sub-optimal IYCF practices. Additionally, sub-optimal diets of children were linked to traditional food preparation methods such as long periods of boiling foods which lead to loss of nutrients, as well as unwillingness to change inappropriate child feeding practices. There was also a reference to the 
increasing involvement of women in work outside the home. Although the national Labour law allows mothers 12 weeks of paid maternity leave, the 2014 DHS indicates that only $9 \%$ of working mothers reported entitlement to paid maternity leave in the past 12 months(Ghana Statistical Service (GSS) et al., 2015). Another 12 percent were able to access maternity leave but without pay. IDI respondents believed that working outside the home separates caregivers from their children, and thus, adversely affects the way children are fed. These changes were identified as gaps in children's diets that need to be addressed.

Regarding child anemia, a micronutrient powder distribution program, although limited in its geographic coverage to Northern Ghana, was considered as an important intervention that has contributed to anemia reduction in that part of the country. A national iron and folate supplementation program to reduce anemia among school-age girls has only recently begun (2017) but was also considered as an important intervention to address anemia in children born to adolescent mothers.

\subsection{Type and coverage of nutrition-sensitive interventions}

Nutrition-sensitive interventions which address the underlying causes of malnutrition were rarely mentioned as a driver of stunting and anemia change in Ghana by stakeholders during interviews. However, a few respondents identified increased access to water, sanitation, and hygiene services in specific regions as important actions linked to improved stunting and anemia. There was mention of the important role of mainstreaming nutrition into other sector activities such as social protection (school feeding, cash transfer), and agriculture. Concerning agriculture, the main link was improved food security, attributed to the Feed the Future project implemented by the USAID in Northern Ghana. Also, in Northern Ghana, and more recently in the Ashanti region, provision of dry home rations by WFP through schools, and to pregnant women, was considered important for addressing food insecurity. Elsewhere in Ghana, food processing technology transfer and community irrigation schemes were implemented by the Ministry of Food and Agriculture and were indicated as important linkages to address food insecurity.

\subsection{Socio-demographic drivers of change}

A range of socio-demographic changes was linked with improved outcomes in stunting and anemia, although respondents could not provide specific evidence for these. These opinions are supported by desk review evidence that was identified in the existing literature. They included improved education access and education level (Ghana statistical Service (GSS), 2014, 2018; Ghana Statistical Service (GSS) et al., 2015; Ghana Statistical Service (GSS) et al., 2009), reduced poverty rate (Ghana Statistical Service (GSS), 2018), improved access to information and communication (Frempong, 2012), and a free economy and trade policies. Others were leadership and governance, a democratic political environment, and better access to health services. Particularly, reduction in population size at the household level was linked with reduced stunting in households in southern Ghana (Ghana Statistical Service (GSS) et al., 2015; Ghana Statistical Service (GSS) et al., 2009).

\subsection{Leadership, Coordination, and capacity across sectors}

\subsubsection{Horizontal and vertical coherence}

Until 2011, the GHS's Nutrition Department was the sole lead agency that coordinated and implemented nutrition actions. The GHS had been leading a national nutrition partners coordination committee (NANUPACC) that included government, academia, civil society, and United Nations agencies. The NANUPACC met on an ad hoc basis to provide technical and financial guidance as well as advocacy for nutrition activities at the national level. In addition, the GHS Director-General convenes the National Child Health Coordinating Body (NCHCB) which focuses on child health program planning, budgeting, and monitoring, including nutrition actions (UN 'Renewed Efforts against Child Hunger and Undernutrition' (REACH), 2014).

The Nutrition Department's actions are focused mainly on advocacy, program design, monitoring and evaluation, and coordination of health-related nutrition actions (Nwafor, 2018). These actions are implemented under the leadership of a Deputy Director, working with a team of specialists assigned specific tasks. There is limited information on nutrition coordination at the subnational level. At the regional and district levels, there are nutrition officers who are assigned responsibility for leading program implementation and monitoring.

In 2011, when Ghana signed up to be part of the SUN movement, a SUN Cross-Sectoral Planning Group (CSPG) was formed which included national-level Government Ministries, United Nations agencies, Civil Society Organizations, Academia/Research, and Donors and their implementing agencies. The CSPG is administratively coordinated by the NDPC and led by a national SUN Focal Point. The CSPG was instrumental in the finalization of the national nutrition policy.

One historical example of a functional coordination mechanism identified was the National Food Fortification Alliance which was established in 2003 to coordinate the national food fortification program nationwide, as a public-private partnership initiative. (Nyumuah et al., 2012) 
The Alliance included government and United Nations agencies, business sector associations, consumer associations, and research institutions. More recently, the government supported the establishment of another nutritionrelevant PPP initiative, the Obaasima fortification standard in 2016. (Association of Ghana Industries (AGI), 2017) Obaasima is a food fortification standard that allows private sector partners to collaborate on producing micronutrient-fortified foods targeting women of reproductive age. The initiative allows participating manufacturers to display a quality seal on processed foods fortified with 18 micronutrients if they meet production standards. Since its commencement, the seal has been used on selected food products that are already available on the market. However, currently, there is no functional coordination mechanism that engages the private sector on nutrition issues (Pittore \& Aryeetey, 2016).

Specifically, for anemia, a micronutrient task team (MTT) was established in 2015 to review policies on micronutrient interventions, and to align them to efforts to address anemia. (Smith Fawzi et al., 2019) The MTT was led by GHS and included partners from Reproductive and Child Health (RCH), WASH, NTD, NMCP, research institutions, UN agencies, Donors, and implementing agencies. Other coordination platforms have been previously established for specific nutrition outcomes. For example, there is a national salt iodization committee that is convened by the Ministry of Trade and Industry. This committee involves various sectors relevant to implementing universal salt iodization including GHS, Police Service, Revenue Authority, Association of Salt producers, Universities/research institutes, UNICEF, and MLGRD. There is also an IYCF task team that comprises various partners including WHO, UNICEF, GHS, and the Pediatric Society of Ghana.

Although there is limited information on the coordination of nutrition actions at national and sub-national levels, the desk review evidence and stakeholder interviews revealed important gaps in the governance of nutrition in Ghana. The report of a 2011 study to review nutrition-implementing institutions in Ghana showed that there was a lack of interministerial coordination, failure of interagency coordination, and a fragmented landscape of loosely held informal groups acting without any institutional basis(Pinto, 2011). It also indicated that engagement between the Nutrition Department with its partners occurs informally, depending on the nutrition issue to be addressed.

The study also indicated that the NANUPACC, which coordinates partners at the national level, meets on an ad hoc basis. At the regional and district levels, there are nutrition officers who are assigned responsibility for leading program implementation and monitoring. The $N N P$ proposes the establishment of multi-sectoral regional and district coordinating units as well as regional and district nutrition focal persons (Government of Ghana, 2016). However, these coordinating platforms have not been established.

\subsection{Stakeholder engagement}

From the net-map interview, a large and varied number $(n=103)$ of institutional actors across multiple sectors (Government, Donor, Non-Governmental Organization (NGOs)/ civil society, United Nations agencies, private sector institutions, and research/academia) were identified to be involved in the aforementioned policies and programs to address child stunting and anemia (Table 4). A quarter of identified institutions were GHS units (Fig. 5). In addition, fifteen individuals were identified as champions and advocates with in-depth knowledge and capacity to influence stunting and anemia and policies and programming. Among the thirtyseven institutional actors who were reported to influence the network (Fig. 6), GHS was considered the most influential due to its ability to engage with multiple partners as well as human resource capacity for delivering services. Other high influence actors were Global Affairs Canada (GAC) (ranked for the ability to engage directly with the government as well as the ability to implement programs directly) and UNICEF (ranked for being a major funder of maternal and child health programs and for their capacity to use data and technical assistance to influence policy and program implementation). The role of GHS in stunting and anemia control was identified as program coordination and implementation related to dietary counseling, and treatment of infections. Roles identified for USAID and GAC were funding.

Figure 5 shows the network of 48 actors connected by 66 unique links relevant for stunting and anemia control in Ghana. Interview participants could not identify links for the remaining stakeholders. Overall, there were many more actors and connections around stunting than anemia. About half (53\%) of the links were reported regarding funding for stunting $(n=35)$. Formal command represented the secondhighest frequency of link types $(n=12)$; advocacy and evidence for stunting involved 10 links in the network. Advocacy and evidence for anemia had the least number of links $(3 \% ; n=2)$. GHS has the highest overall in-degree centrality (17), an indication of its prominence compared to other actors in the network. Ministry of Health (10), UNICEF (9), and USAID (8) had the highest out-degree centrality in the network, indicating that these actors had the highest tendency to provide input to others in the network.

\subsection{Institutional and individual capacity}

There were mixed opinions from stakeholder interviews regarding the role of capacity in explaining the decline in both stunting and anemia prevalence. On one hand, there was recognition of improvements in capacity for nutrition 
Table 4 List of actor acronyms, full names and actor groups identified in net-map interview

\begin{tabular}{|c|c|c|c|}
\hline No. & ID/Label & Actor full name & Actor group \\
\hline 1 & USAID & United States Agency for International Development & Donor Development partner \\
\hline 2 & JICA & Japan International Cooperation Agency & Donor Development partner \\
\hline 3 & GAC & Global Affairs Canada & Donor Development partner \\
\hline 4 & EU & European Union & Donor Development partner \\
\hline 5 & DANIDA & Danish International Development Agency & Donor Development partner \\
\hline 6 & KOICA & Korea International Development Agency & Donor Development partner \\
\hline 7 & Global Fund & The Global Fund to Fight AIDS, Tuberculosis and Malaria & Donor Development partner \\
\hline 8 & DFID & Department for International Development & Donor Development partner \\
\hline 9 & ADRA & Adventist Development and Relief Agency & NGO \\
\hline 10 & PATH & Path Ghana & NGO \\
\hline 11 & WV & World Vision Ghana & NGO \\
\hline 12 & PLAN & Plan International Ghana & NGO \\
\hline 13 & FBHPders & FBH Providers & NGO \\
\hline 14 & CoalofNGOs & Coalition of Non-governmental Organisation & NGO \\
\hline 15 & CRS & Catholic Relief Services & NGO \\
\hline 16 & RotaryInt & Rotary International & NGO \\
\hline 17 & GhRedCros & Ghana Red Cross Society & NGO \\
\hline 18 & GHASSUN & Coalition of Non-governmental Organisations in Nutrition & NGO \\
\hline 19 & WaterAid & Water Aid & NGO \\
\hline 20 & YEDENT & Yedent Group of Companies & Private \\
\hline 21 & ManuDistrs & Manufacturers and Distributors & Private \\
\hline 22 & FlourMillrs & Flour Millers & Private \\
\hline 23 & $\mathrm{MOH}$ & Ministry of Health & Government \\
\hline 24 & MinOTIdtry & Ministry of Trade and Industry & Government \\
\hline 25 & GSAuthority & Ghana Standard Authority & Government \\
\hline 26 & NHIS & National Health Insurance Scheme & Government \\
\hline 27 & TeachHOSP & Teaching Hospitals & Government \\
\hline 28 & FDA & Food and Drugs Authority & Government \\
\hline 29 & MinoFinance & Ministry of Finance & Government \\
\hline 30 & MOFA & Ministry of Food and Agriculture Women in Agricultural Development & Government \\
\hline 31 & GHS & Ghana Health Service & Government \\
\hline 32 & Med\&Dent & Ghana Medical and Dental Council & Government \\
\hline 33 & PharmCoun & Pharmacy Council & Government \\
\hline 34 & Nurs \& Mid & Nurse and Midwifery Council & Government \\
\hline 35 & Min of Plan & Ministry of Planning & Government \\
\hline 36 & LGov(MMDAs) & Ministry of Local Government (Metropolitan, Municipal and District Assembly) & Government \\
\hline 37 & NDPC & National Development Planning Commission & Government \\
\hline 38 & GhEdServ & Ghana Education Service & Government \\
\hline 39 & Fish Comsion & Fisheries Commission & Government \\
\hline 40 & World Bank & World Bank & UN \\
\hline 41 & WHO & World Health Organization & UN \\
\hline 42 & WFP & World Food Programme & UN \\
\hline 43 & UNICEF & United Nations International Children's Emergency Fund & UN \\
\hline 44 & FAO & Food and Agriculture Organization & UN \\
\hline 45 & IITA & The International Institute of Tropical Agriculture & Research/Academia \\
\hline 46 & CSIR & Council for Scientific and Industrial Research & Research/Academia \\
\hline 47 & FRI/CSIR & Food Research Institute/ Council for Scientific and Industrial Research & Research/Academia \\
\hline 48 & SARI/CSIR & Savanna Agriculture Research Institute/ Council for Scientific and Industrial Research & Research/Academia \\
\hline 49 & Univ of Gha & University of Ghana & Research/Academia \\
\hline 50 & Noguchi & Noguchi Memorial Institute for Medical Research & Research/Academia \\
\hline
\end{tabular}


Table 4 (continued)

\begin{tabular}{|c|c|c|c|}
\hline No. & ID/Label & Actor full name & Actor group \\
\hline 51 & UDS & University for Development Studies & Research/Academia \\
\hline 52 & ALartey_FAO & Anna Lartey Food and Agriculture Organisation & Opinion leader \\
\hline 53 & EAmaful_GHS & Esi Amoaful Ghana Health Service & Opinion leader \\
\hline 54 & ISMoses_GHS & Isabella Sagoe-Moses Ghana Health Service & Opinion leader \\
\hline 55 & KateQ_GHS & Kate Quarshie Ghana Health Service Anemia & Opinion leader \\
\hline 56 & Okwabi_GHS & Mrs. Okwabi Ghana Health Service & Opinion leader \\
\hline 57 & Akosa_GHS & Prof. Badu Akosa/Ghana Health Service & Opinion leader \\
\hline 58 & PAddy_MOFA & Paulina Addy/Ministry of Food and Agriculture & Opinion leader \\
\hline 59 & MGAmngor_CSIR & Mary Glover-Amengor/ Council for Scientific and Industrial Research & Opinion leader \\
\hline 60 & PMSteiner_UG & Prof Matilda Steiner /University of Ghana & Opinion leader \\
\hline 61 & FirstLady & Rebecca Akuffo-Addo/Ghana First Lady & Opinion leader \\
\hline 62 & M Qnmther & Mankessim Queenmother & Opinion leader \\
\hline 63 & GAnti_Media & Gifty Anti Media & Opinion leader \\
\hline 64 & MYaaNyarko & Maame Yaa Nyarko & Opinion leader \\
\hline 65 & Pres. Kuff & Former President John Agyekum Kuffour & Opinion leader \\
\hline 66 & Rev. JAryee & Rev. Joyce Aryee & Opinion leader \\
\hline 67 & GIZ & Deutsche Gesellschaft fur Internatonale Zusammenarbeit (GIZ) GmbH & Donor Development partner \\
\hline 68 & GINAN & Ghana Infant Nutrition Action Network- World Alliance for Breastfeeding Action & NGO \\
\hline 69 & CARE & Care International Ghana & NGO \\
\hline 70 & TechnoServ & Techno Serve & NGO \\
\hline 71 & Hngr Alliance & Hunger Alliance of Ghana & NGO \\
\hline 72 & Food Span & Food Span & NGO \\
\hline 73 & Implmn Partrs & Implementing Partners & NGO \\
\hline 74 & SNV & SNV Netherlands Development Organisation & NGO \\
\hline 75 & Peat Frmrs Ass. & Peasant Farmers Association & NGO \\
\hline 76 & Hngr Proj & Hunger Project & NGO \\
\hline 77 & SEND FOUND & Social Enterprise Development (SEND) Foundation of West Africa & NGO \\
\hline 78 & PCD & The Partnership for Child Development & NGO \\
\hline 79 & GCSforSUN & Ghana Civil Society for Scaling up Nutrition & NGO \\
\hline 80 & FHI360 & FHI360 & NGO \\
\hline 81 & Frmr Basd Org & Farmer Based Organizations & NGO \\
\hline 82 & AGI & Association of Ghana Industries & Private \\
\hline 83 & FINARFOODS & Finar Foods & Private \\
\hline 84 & NESTLE & Nestle Ghana Ltd & Private \\
\hline 85 & Proj Pnut But & Project Peanut Butter & Private sector \\
\hline 86 & GHS_PRO & Ghana Health Service Health Promotion Unit & Government \\
\hline 87 & GHS_MAL & Ghana Health Service Malaria Control Programme & Government \\
\hline 88 & GHS_NUTR & Ghana Health Service Nutrition Department & Government \\
\hline 89 & GHS_RCH & Ghana Health Service Reproductive and Child Health Unit & Government \\
\hline 90 & GSS & Ghana Statistical Services & Government \\
\hline 91 & Min of Fish & Ministry of Fisheries & Government \\
\hline 92 & Min of Wat \& Sani & Ministry of Water and Sanitation & Government \\
\hline 93 & CHAG & Christian Health Association of Ghana & Government \\
\hline 94 & Gh AIDS Comm & Ghana AIDS Commission & Government \\
\hline 95 & UNHCR & United Nations High Commissioner for Refugees & UN \\
\hline 96 & UNFPA & United Nations Population Fund & UN \\
\hline 97 & KHRI & Kintampo Health Research Institute & Research/Academia \\
\hline 98 & SUN_ACAD & Scaling Up Nutrition Academic Platform & Research/Academia \\
\hline 99 & KNUST & Kwame Nkrumah University of Science and Technology & Research/Academia \\
\hline 100 & Crp R Inst_CSIR & Crop Research Institute/ Council for Scientific and Industrial Research & Research/Academia \\
\hline
\end{tabular}


Table 4 (continued)

\begin{tabular}{llll}
\hline No. & ID/Label & Actor full name & Actor group \\
\hline 101 & Soil R Inst_CSIR & Soil Research Institute/ Council for Scientific and Industrial Research & Research/Academia \\
102 & Wat R Inst_CSIR & Water Research Institute/ Council for Scientific and Industrial Research & Research/Academia \\
103 & BNARI & Biotechnology and Nuclear Agriculture Research Institute & Research/Academia \\
\hline
\end{tabular}

service delivery in the health sector. IDI respondents listed the increased number and distribution of nutrition technical officers as a contributing factor to the observed improvement in outcomes. It was reported that currently, every district has at least one nutrition technical officer. In addition, increased in-service training opportunities have resulted in improved nutrition competence for nutrition officers as well as other staff working in the health sector, by enhancing their technical competence for delivering nutrition interventions and services. This in-service nutrition technical training was reported to have occurred throughout the country. Further, pre-service training was enhanced through an update of nutrition curricula along with capacity building for teachers in health training schools (i.e., nursing and midwifery training schools, and health technical officers training schools). At the point of service delivery, facilities were provided the job-training materials, job aids, clinical decision tools, and mobility support for staff training overseas.

In addition to the technical competence, leaders and decisionmakers from multiple sectors were supported to participate in events and meetings to build their functional capacity in

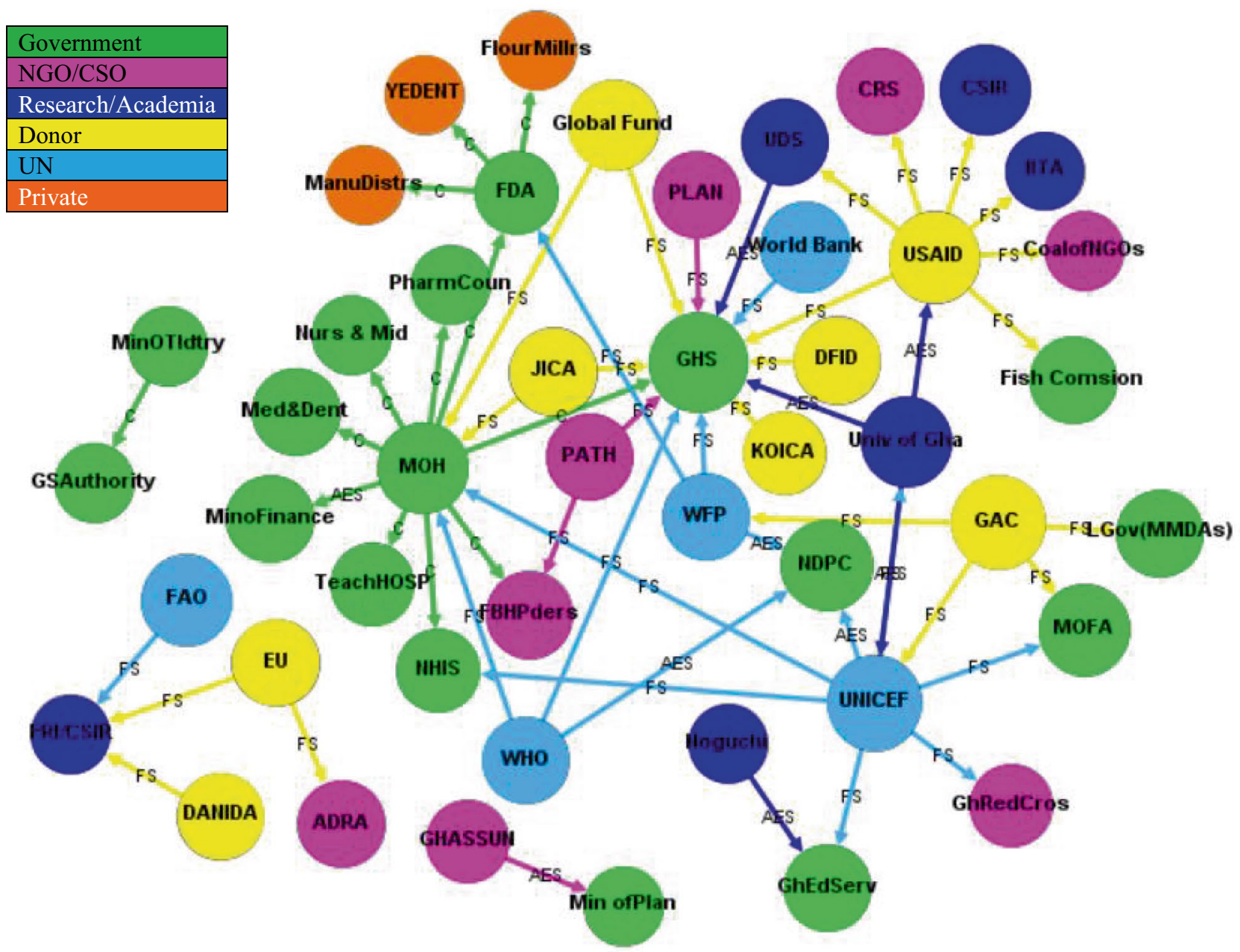

Fig. 5 Map of stakeholders and their linkages regarding stunting and anemia policy and programs in Ghana 


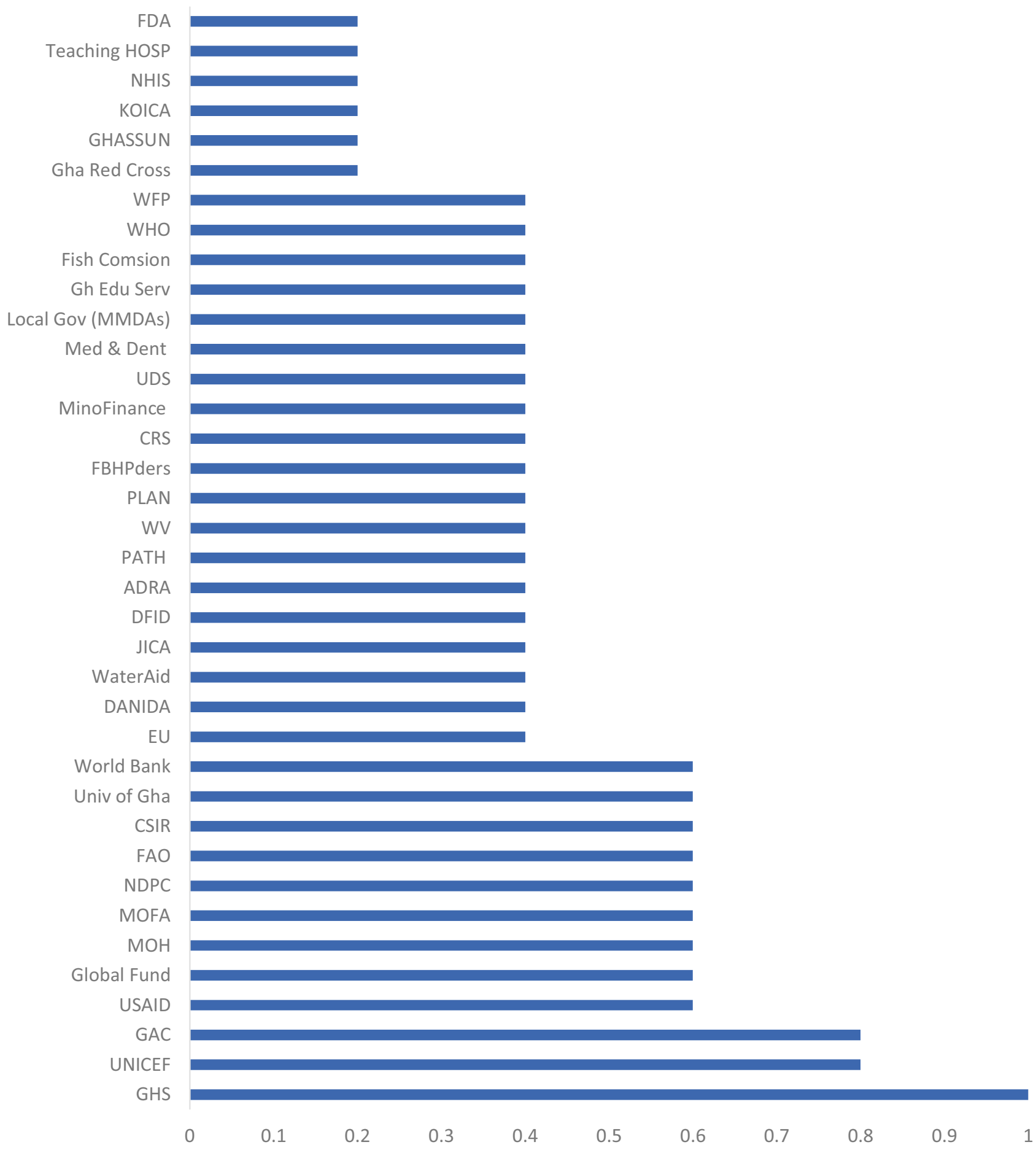

Fig. 6 Relative influence of stakeholders involved in stunting and anemia policies and programs in Ghana

developing nutrition policies and plans, as well as program implementation. These learning opportunities included multiple learning trips to Japan and Brazil, participation in the global gatherings of the SUN Movement, and other similar global and regional events. Although it has only recently begun (2017), the health sector's Maternal, Child, Neonatal, and Adolescent Health and Nutrition Conference was considered an important contribution to nutrition capacity building.

On the other hand, some stakeholders expressed dissatisfaction with the level of capacity for addressing malnutrition among young children in Ghana. They believed that even more robust improvement in child nutrition could be 
achieved by filling the gaps in technical capacity caused by high staff attrition, as well as address inadequate skills for counseling, community mobilization, data analysis, and leading multi-disciplinary teams. The desk review evidence also shows that there are unresolved institutional capacity gaps including limited capacity for intersectoral coordination, identifying, and creating visibility of malnutrition, generating a shared interest to address malnutrition across sectors, and leveraging funding for prevention and management of malnutrition.

\subsection{Limited understanding of drivers of stunting and anemia}

Regarding stunting, the IDI evidence indicates that there is limited appreciation of what causes stunting among both decision-makers and the general public. Further, stunting is not yet known and is considered an important public health and human development issue among some key stakeholders. Thus, it is not considered in decision-making when solving development issues. In the case of anemia, it was indicated that there is limited understanding of the anemia situation. Some stakeholders were surprised that although the key recommended interventions have been implemented, anemia rates remain high. Thus, it is not clear what else should be done to address anemia.

\subsection{Financing nutrition actions}

Some interview respondents believed that insufficient government funding of nutrition resulted in a heavy reliance on donor funding. Although there is an indication that the government is beginning to increase funding to nutrition, a huge gap in nutrition investment by the government remains (Laar et al., 2015). In the existing activity-based budgeting system of the Ministry of Finance, there is no specific budgetary allocation by the government to nutrition. In this system, funding allocation for nutrition actions is not disaggregated; it is often buried in higher-level ministerial budgets, making it difficult to determine government allocation and expenditure on nutrition. Therefore, nutrition interventions are mainly supported by external donors. As a result, interventions are often implemented in geographical settings that have been prioritized for funding by external donors. The inability of the Ghana government to provide funding to initiate or sustain proven strategies affects the capacity to scale them up or to ensure effective implementation. For example, limited funding affects the ability to conduct supportive supervision needed for program effectiveness and efficiency.
An additional challenge to funding nutrition is that since Ghana became a middle-income country in 2012, it has become more difficult for donor agencies to raise funds to support nutrition-related interventions in Ghana. This fundraising challenge has become even more challenging to justify because the Government of Ghana, since 2017, has been pursuing an agenda of 'Ghana Beyond Aid', thus, creating inertia for donors to support social interventions.

\subsection{Monitoring of intervention coverage and outcomes}

The IDI and desk review evidence showed that there is no integrated nutrition surveillance system for tracking implementation and coverage of interventions across sectors. However, different sectors have monitoring and evaluation plans for specific programs. The health system's District Health Information Management System (DHIMS) monitors health programs (including nutrition) but is not linked to information systems in other sectors like agriculture, social protection, education, and others. Further, DHIMS data is only available to authorize public health officials. Based on DHIMS, the GHS produces an annual health report on sector programs, including nutrition-relevant information (Ghana Health Services (GHS), 2012; UNICEF, 2012).

These limitations exist despite a recognized need for monitoring. For example, the GHS's Child Health Strategy indicates the need for monitoring of anemia rate among children (Ministry of Health (MoH), 2007a). The NNP also refers to a system of monitoring and evaluation (M\&E) of nutrition strategies over 5-year cycles, based on a national monitoring and evaluation framework (Ministry of Health $(\mathrm{MoH}), 2014)$. In the agriculture sector, the METASIP (2011-2015) (Ministry of Food and Agriculture (MoFA), 2010) refers to an internal $M \& E$ system as the basis for determining progress in nutrition.

The DHS and MICS, which are implemented almost regularly every 5 years, provide coverage indicators programs such as micronutrient supplementation programs, bed net distribution, and WASH (Ghana Statistical Service (GSS), 2011; Ghana Statistical Service (GSS) et al., 2015; Ghana Statistical Service (GSS) et al., 2009; Ghana Statistical Service (GSS). 2018). Overall, there remains a gap in information systems to guide decision-making regarding interventions that address CS\&A, across relevant sectors.

Stakeholders indicated that there are insufficient resources to scale up interventions, in terms of geographic coverage, intensity, and sufficient quality. For example, although there has been an improvement in the number of districtlevel nutrition officers, interventions are often not devolved to sub-district levels. Thus, sub-districts and communities have limited access to nutrition services. Another aspect of 
limited intervention coverage is that interventions are often implemented as localized projects in selected settings, based on donor funding. Although some of these interventions are effective, when the funding runs out, they are rarely scaled up to other settings, due to lack of resources. An example of this issue that was mentioned was the Nutrition and Malaria Intervention which was implemented only in selected districts in the three Northern regions and Volta region.

The food fortification program evaluation report noted that evaluation of the program should be linked with existing M\&E systems, although it's not clear what these existing systems are (Ministry of Health $(\mathrm{MoH}), 2014)$. The fortification program also outlines a process for both Internal (i.e., within the industry) and external (FDA, GHS Nutrition Department) M\&E systems to be linked with the regulatory monitoring system. It also proposed monthly visits by government inspectors to flour and oil mills for technical audits, biannual post-market surveillance nationwide of flour and oil samples in a selected market, shops by FDA, and placement of monitoring systems to monitor iodine levels in salt at production sites (Government of Ghana, 2016). Some reviewed documents indicated demand for nutrition surveillance and program data. All these documents point to the need to monitor systems across sectors (Brantuo et al., 2009; Government of Ghana, 2016).

\subsection{Accountability to citizens}

There was limited evidence of accountability to the public regarding actions to address stunting and anemia among children in Ghana. The GHS publishes an annual report of its programs (Ghana Health Services (GHS), 2012; UNICEF, 2012). While this report is useful to technical officers working in the health sector, the language is technical and not friendly for civic organizations or the lay public to use to demand public accountability. Although public sector agencies involved in stunting- and anemia-related intervention have websites, these websites do not provide easily accessible information on their programs. In the absence of publicly available information on the progress of interventions, as well as the lack of a mechanism for accountability, there is limited opportunity for the public to demand accountability on progress in nutrition interventions to address stunting and anemia.

Since 2011, GHACCSUN, a civil society organization, has focused its activities on championing the goals of the SUN movement in Ghana.(Management Technologies Consutants, 2013). As a member of the CSPG, GHACCSUN has been actively advocating for repositioning nutrition to have a higher place of priority in Ghana's development agenda as well as creating public awareness of undernutrition among vulnerable groups. GHACCSUN has also mapped civil society organizations involved in nutrition in Ghana to enable easy quantification of efforts to address child undernutrition (Management Technologies Consutants, 2013). Similarly, the SUN academic platform, which is also part of the SUN CSPG has been contributing evidence and capacity building for the SUN movement's activities in Ghana (R. N. Aryeetey et al., 2015). The various universities have also been implementing a range of research activities whose findings were disseminated to various stakeholders and these were considered important contributions to decision making for stunting and anemia control.

\section{Discussion}

The current study describes the processes and actions that explain why stunting and anemia declined in Ghana between 2009 and 2018. The evidence shows that stunting reduction over time was linked with multiple actions. The key factors that were positively correlated with CS\&A included increased availability and utilization of health services (including antenatal care visits and vaccination of children), access to WASH services (particularly access to potable water and handwashing), and availability of insecticide-treated bed-net(s) in households. Improvement and access to these services could be attributed, partly, to a general improvement in the living situation of Ghanaians; this situation has been attributed to a stable political situation, good economic growth, and increased access to the infrastructure needed for basic living(Booth et al., 2005; Mills, 2018). In addition, a combination of policies and programs implemented across multiple sectors may be important drivers. The fact that some of these interventions have been positive contributors, even though they were not designed to contribute to CS\&A is noteworthy and suggests that with more targeted approaches, even more positive outcomes can be expected. In particular, the GHS interventions such as the provision of preventive health services including micronutrient supplementation, distribution of free bed nets, and expanded economic access to health services through the health insurance scheme were identified as important drivers.

The observed changes were not limited to the specified decade; they are possibly resulting from the cumulative effect of actions and circumstances that predates the decade that was the focus of the study (Brantuo et al., 2009; Ghartey, 2010). Earlier reviews of nutrition policies and programs reported initiation and scale-up of nutrition-specific and nutrition-sensitive interventions that have contributed not only to the improved outcomes but also to strengthening institutional and capacity to deliver nutrition-relevant services (Brantuo et al., 2009; Ghartey, 2010). Two important characteristics of the change in outcomes are noteworthy. The first is that the observed changes in nutrition outcomes, 
particularly stunting, have occurred over a long period. This is not surprising given that stunting often results from chronic exposure to adverse dietary and disease situations (de Onis \& Branca, 2016; McGovern et al., 2017). Secondly, there was no singular action that contributed to the reduction of either stunting or anemia. We observed that the interventions which were designed to address stunting and anemia (particularly in the health sector) and those which did not have stunting and anemia reduction goals were necessary to achieve the observed outcomes. These findings provide useful lessons for future planning and action to address child undernutrition in Ghana and elsewhere.

It is also important to note that the current analysis demonstrates that some interventions may be more important in stimulating greater gains in stunting and anemia reduction. In particular, there was a convergence of evidence around interventions that reduce the risk of infectious morbidity (including sleeping under insecticide-treated nets, improved access to potable water, and full immunization of children), improved living conditions (including increased household assets, maternal education, physical and economic access to health and other social services), and improved quality of health care (including enhanced utilization of maternity care services), all important contributors to reduced undernutrition in young children. Although dietary interventions were implemented during the period under observation, their contribution to the observed change may have been diminished by the poor performance in dietary outcomes during the period. Perhaps, even more, robust performance would have been observed if there was better performance in breastfeeding and complementary feeding of young children.

Improvement in key basic drivers of undernutrition may further enhance the opportunity for reducing undernutrition in children. Key barriers that need to be addressed at the basic level include enhancing the capacity of actors implementing nutrition across all relevant sectors. This deficiency is not unique to Ghana. Recent studies have shown that nutrition implementation capacity gaps are a key challenge globally, but even more prevalent in sub-Saharan Africa (Aryeetey et al., 2015; Sodjinou et al., 2014a, 2014b; Sunguya et al., 2013). Interventions to address capacity in nutrition should be comprehensive and not only limited to health care workers, as was observed in this study. Capacity-building should go beyond training on individual technical capacity; it should also address identified gaps in the functional and institutional capacity that is needed to address broader issues related to nutrition governance and leadership across sectors and institutions (Fanzo et al., 2015; Jerling et al., 2016). Further, such capacity should not be built only at the apex alone. There is a need to empower actors at the sub-national levels to ensure that policies and programs can be implemented more effectively. Lessons on this can be learned from the SUN movement's capacitybuilding initiatives in various SUN countries.

Another important capacity gap identified by this study is insufficient government funding for nutrition. Unlike the global level where nutrition advocacy and prioritization has resulted in increased funding of nutrition initiatives, in Ghana, prioritization has not yielded benefits in improved funding. This challenge, if unaddressed, can have adverse impacts on program scale-up and impact as well as diminishing the visibility that nutrition currently enjoys. Capacity building is therefore needed to identify innovative ways to ensure that funding allocated to sectors that do not work on diets and diseases, can be used in ways that are nutrition-sensitive. In addition, there is a need to restructure the funding mechanisms in a way that allows tracking of funds allocated to nutrition across sectors to be able to determine funds spent on nutritionspecific and nutrition-sensitive interventions. This is another area that lessons can be learned through SUN movement initiatives across countries (Picanyol et al., 2015).

Perhaps, one of the most pressing challenges to achieving further declines in child undernutrition is the lack of coordination across relevant sectors. Central to this issue is the absence of a functional nutrition governance mechanism that has enough resources and authority to harness resources across government Ministries, Departments, and Agencies as well as non-government partners. Given the vested interests across various agencies regarding their historical roles, as well as the protective attitudes to limited resources allocated by the central government to these agencies, there is a need for a high-level political intervention as a demonstration of commitment to overhaul nutrition governance in Ghana. Such high-level political interventions have been shown to ignite better funding and program implementation in other similar settings (Food and nutrition technical assistance III Project (FANTA), 2017; te Lintelo et al., 2020).

The current study shows that stunting was prioritized more than anemia. It may be the reason why the magnitude of stunting decline was greater than anemia. It is not possible to prioritize every issue. However, given that the two outcomes share similar drivers, it may be useful for future advocacy and decision making to focus more attention on anemia control, while continuing to monitor and strengthen efforts to address stunting.

The main limitations of the current study are that it focuses on the 10 years before 2019, although some of the changes in outcomes and drivers have occurred over a longer period. For example, some of the identified policies and programs that drove change predated 2009, as indicated in an earlier study of the nutrition landscape in Ghana(Brantuo et al., 2009; Ghartey, 2010). Since such actions will not be considered, their effect may be overlooked or underestimated. Another important limitation is that the end point of 
the decomposition analysis was 2014, the year when the latest DHS data was collected. As a result, more recent changes in drivers and outcomes have not been considered in the current analysis. It is possible that if more recent data were available, the findings from the decomposition analysis will be different from what has been reported.

Despite the limitations outlined above, the current study makes an important contribution to understanding the drivers of stunting and anemia in Ghana. Indeed, the current study is the first to systematically evaluate evidence on drivers of change in CS\&A in Ghana. One key strength of this study is the use of the stories of change approach which enables triangulation of a range of qualitative and quantitative research methods in a way that brings out the 'story' of CS\&A as it unfolded in the decade of interest. The findings can also serve as a guide for planning and program implementation to further reduce child stunting and to stimulate renewed focus on child anemia control.

\section{Conclusions}

The current study shows that overall, both stunting and anemia in young children has declined at the national level. However, the declines have not been uniform across regions and socio-demographic subgroups. These changes have occurred while improvements were observed in underlying and basic drivers of child nutrition. In addition to a general improvement in the socio-economic situation in Ghana, over the past decade, the observed changes could be attributed to policy and program interventions across multiple sectors, notably IYCF promotion, WASH, social protection, and health. These interventions were stimulated by awareness creation that led to increased prioritization of stunting; child anemia was, however, not given similar attention during this period. In addition, decomposition analysis identified changes in household wealth, use of antenatal services during pregnancy, maternal education, and immunization as important drivers of change in anemia. Regarding stunting, the key drivers of change were the use of bed nets, household wealth, and utilization of antenatal services during pregnancy. Despite the improved outcomes, there remain important gaps that need to be addressed including funding, capacity, and coordination across sectors and quality of diets of young children.

Supplementary information The online version contains supplementary material available at https://doi.org/10.1007/s12571-021-01232-1.

Acknowledgements We gratefully acknowledge Beverly Abreu and Abena Engmann for administrative Support. We are grateful to Opeyemi Lasisi, Marian Offei, Yakubu Adam, Nathaniel Coleman, and Delia Bandoh who transcribed and coded audio records of interviews, and Derek Headey who provided support with regression and decomposition analysis. We acknowledge all respondents from Government and non-government agencies who provided information and made time to participate in interviews and stakeholder meetings that contributed to data gathering. We acknowledge the immense contribution of Noora Aberman for her support with implementing and analysing the Net-maps.

Author contributions RA, MvdB, and NN designed the study. RA and AAY collected and analysed the data. MvdB, LB, MT and NN contributed to data analysis and interpretation. RA drafted the paper and had primary responsibility for the final content. All authors read and approved the final manuscript.

Funding Financial support for this study was provided by IFPRI (2018X161.GHA).

Data availability All quantitative and qualitative data supporting the findings of this study are available from the corresponding author (R.A.), on request.

\section{Declarations}

Conflict of interest The authors report no conflict of interest.

Open Access This article is licensed under a Creative Commons Attribution 4.0 International License, which permits use, sharing, adaptation, distribution and reproduction in any medium or format, as long as you give appropriate credit to the original author(s) and the source, provide a link to the Creative Commons licence, and indicate if changes were made. The images or other third party material in this article are included in the article's Creative Commons licence, unless indicated otherwise in a credit line to the material. If material is not included in the article's Creative Commons licence and your intended use is not permitted by statutory regulation or exceeds the permitted use, you will need to obtain permission directly from the copyright holder. To view a copy of this licence, visit http://creativecommons.org/licenses/by/4.0/.

\section{References}

Allali, S., Brousse, V., Sacri, A. S., Chalumeau, M., \& de Montalembert, M. (2017). Anemia in children: Prevalence, causes, diagnostic work-up, and long-term consequences. Expert Review of Hematology, 10(11), 1023-1028. https://doi.org/10.1080/17474086.2017.1354696

Aryeetey, R., Adeyemi, O., Bold, M. V. D., Becquey, E., Nisbett, N., \& Turowska, Z. (2020). Transform Nutrition West Africa's Stories of Change in Nutrition - the story so far in Ghana and Burkina Faso. Retrieved from https://westafrica.transformnutrition. org/news/transform-nutrition-west-africas-stories-of-changein-nutrition-the-story-so-far-in-ghana-and-burkina-faso/

Aryeetey, R. N., Laar, A., Zotor, F. (2015). Capacity for scaling up nutrition: A focus on pre-service training in West Africa and a Ghanaian case study. The Proceedings of the Nutrition Society, 1-5.https://doi.org/10.1017/s0029665114001748

Association of Ghana Industries (AGI). (2017). Code of Practice for Micronutrient Fortification of Processed Packaged Foods. Accra AGI

Bailey, H. (2015). Stories of Change. Brighton, United Kingdom: Insitute of Development Studies

Black, R., Allen, L., Bhutta, Z., Caulfield, L., de Onis, M., Ezzati, M., Maternal and Child Undernutrition Study Group. (2008). 
Maternal and child undernutrition: Global and regional exposures and health consequences. Lancet, 371(9608), 243-260.

Black, R. E., Victora, C. G., Walker, S. P., Bhutta, Z. A., Christian, P., de Onis, M., \& Uauy, R. (2013). Maternal and child undernutrition and overweight in low-income and middle-income countries. Lancet, 382(9890), 427-451. https://doi.org/10.1016/ s0140-6736(13)60937-x

Booth, D., Crook, R., Gyimah-Boadi, E., Killick, T., Luckham, R., \& Boateng, N. (2005). What are the drivers of change in Ghana? Accra: Ghana Center for Democratic Development Retrieved from https://www.odi.org/sites/odi.org.uk/files/odi-assets/publicationsopinion-files/1961.pdf

Brantuo, M., Okwabi, W., Adu-Afuawuah, S., Agyepong, E., Attafuah, N., Brew, G., Ashong, J. (2009). Landscape Analysis of Readiness to Accelerate the Reduction of Maternal and Child Undernutrition in Ghana. SCN News, 37(31-37).

de Onis, M., \& Branca, F. (2016). Childhood stunting: a global perspective. Matern Child Nutr, 12(Suppl 1), 12-26. https://doi.org/ $10.1111 / \mathrm{mcn} .12231$

Fanzo, C. F., Grazioce, M. M., Kraemer, K., Gillespie, S., Johnston, J. L., De Pee, S., \& West, K. P. (2015). Educating and Training a Workforce for Nutrition in a Post-2015 World. Advances in Nutrition, 6, 639-647. https://doi.org/10.3945/an.115.010041

FAO, IFAD, \& WFP (2015). The State of Food Insecurity in the World 2015: Meeting the 2015 international hunger targets: Taking stock of uneven progress. Rome: FAO. https://www.fao.org/publications/ sofi/2015/en/

Food and Agriculture Organisation (FAO), International Fund for Agricultural Development (IFAD), United Nations Children's Fund (UNICEF), World Food Programme (WFP, \& World Health Organization (WHO). (2019). The State of Food Security and Nutrition in the World 2019: Safeguarding against economic slowdowns and downturns. FAO.

Food and nutrition technical assistance III Project (FANTA). (2017). Strengthening Nutrition Governance: FANTA Achievements and Lessons Learned. Washington DC: FHI 360/ FANTA Retrieved from https://www.fantaproject.org/sites/default/files/resources/ FANTA-Nutrition-Governance-report-Aug2017.pdf

Frempong, G. (2012). Understanding what is Happening in ICT in Ghana: A supply- and demand side analysis of the ICT sector. Research ICT Africa Retrieved from https://researchictafrica.net/ publications/Evidence_for_ICT_Policy_Action/Policy_Paper_ 4_-_Understanding_what_is_happening_in_ICT_in_Ghana.pdf

Ghana Health Service (GHS). (2013). Ghana Neglected Tropical Diseases Program: Master Plan (2013-2017). Accra, Ghana: GHS

Ghana Health Service (GHS). (2014). Ghana National Newborn Health Strategy And Action Plan. Accra, Ghana: GHS

Ghana Health Service (GHS), \& United states Agency for International Aid (USAID). (2011). Overview of 2011 Ghana Nutrition PROFILES Results. Retrieved from https://www.fantaproject.org/sites/ default/files/resources/Ghana-Overview-PROFILES-Feb2013.pdf

Ghana Health Service (GHS), United States Agency for International Aid (USAID), Communicate for Health, \& United Nations Children's Fund (UNICEF). (2019). Welcome to Goodlife Live it well. GHS Retrieved from https://www.fhi360.org/sites/default/files/ media/documents/resource-c4h-brochure.pdf

Ghana Health Service (GHS)/National Malaria Control Program (NMCP). (2017). National Malaria Control Programme. Retrieved from http:// www.ghanahealthservice. org/ghs-subcategory.php?cid $=4 \&$ scid $=41$

Ghana Health Services (GHS). (2012). 2011 Annua Report. Accra: GHS Ghana Statistical Service. (2012). Ghana Multiple Indicator Cluster Survey with an Enhanced Malaria Module and Biomarker 2011 Final Report. Accra, Ghana: GSS

Ghana Statistical Service (GSS). (2011). Ghana Multiple Indicator Cluster Survey with an Enhanced Malaria Module and Biomarker 2011 Final Report. Accra: GSS
Ghana statistical Service (GSS). (2014). Ghana Living Standards Round 6: Main Report. Accra: Ghana

Ghana Statistical Service (GSS). (2018). Ghana Living Standards Survey Round 7: Poverty Trends in Ghana (2005-2017). Accra, Ghana: GSS

Ghana Statistical Service (GSS), Ghana Health Service (GHS), \& ICF. (2018). Ghana Maternal Health Survey 2017. Accra: Ghana Statistical Service

Ghana Statistical Service (GSS), Ghana Health Service (GHS), \& ICF International. (2015). Demographic and Health Survey 2014. Rockville, Maryland, USA: GSS, GHS, ICF International

Ghana Statistical Service (GSS), Ghana Health Services (GHS), \& ICF Macro. (2009). Ghana Demographic and Health Survey 2008. Retrieved from Accra:

Ghana Statistical Service (GSS), Ghana Health Services (GHS), \& Macro Inc. (2007). Ghana Maternal Health Survey. Accra: Ghana Statistical Service

Ghana Statistical Service (GSS), Noguchi Memorial Institute for Medical Research (NMIMR), \& Inc, O. M. (2004). Ghana Demographic and Health Survey 2003. Calverton, Maryland: GSS, NMIMR and ORC Macro

Ghana Statistical Service (GSS). (2018). Multiple Indicator Cluster Survey (MICS 2017/2018): Survey Findings Report. Accra, Ghana GSS

Ghartey, A. B. (2010). Nutrition Policy and Programs in Ghana: The Limitation of a Single Sector Approach. Washington, DC: World Bank Retrieved from https://openknowledge.worldbank.org/handle/ 10986/27590

Gillespie, S., Haddad, L., Mannar, V., Menon, P., \& Nisbett, N. (2013). The politics of reducing malnutrition: Building commitment and accelerating progress. Lancet, 382(9891), 552-569. https://doi. org/10.1016/s0140-6736(13)60842-9

Gillespie, S., Hodge, J., Yosef, S., \& Pandya-Lorch, R. (Eds.). (2016). Nourishing Millions: Stories of Change in Nutrition. IFPRI.

Gillespie, S., \& van den Bold, M. (2017). Stories of Change in nutrition: An overview. Global Food Security, 13, 1-11. https://doi. org/10.1016/j.gfs.2017.02.004

Government of Ghana. (2010). Ghana Shared Growth and Development Agenda (GSGDA)-I. Accra Government of Ghana

Government of Ghana (GoG). (2005). Small Communities water and Sanitation Policy. Accra, Ghana: GoG

Government of Ghana (goG). (2010a). National Environmental Sanitation Strategy and Action Plan (NESSAP). Accra, Ghana: GoG

Government of Ghana (GoG). (2010b). Strategic Environmental Sanitation Investment Plan (SESIP). Accra, Ghana: GoG

Government of Ghana (GoG). (2015). Draft National School Feeding Policy. Accra, Ghana: GoG

Government of Ghana. (2016). National Nutrition Policy. Accra: Government of Ghana.,

Headey, D., Hoddinott, J., \& Park, S. (2017). Accounting for nutritional changes in six success stories: A regression-decomposition approach. Global Food Security, 13, 12-20. https://doi.org/10. 1016/j.gfs.2017.02.003

$\mathrm{Hu}$, Y. F. (2005). Efficient and high quality force-directed graph drawing. The Mathematica Journal, 10(37-41).

International Food Policy Research Institute (IFPRI). (2021). Our Approach. Retrieved from https://westafrica.transformnutrition. org/about-us/our-approach/

Jerling, J., Pelletier, D., Fanzo, J., \& Covic, N. (2016). Supporting multisectoral action: Capacity and nutrition leadership challenges facing Africa. In N. Covic \& S. L. Hendriks (Eds.), Achieving a nutrition revolution for Africa: The road to healthier diets and optimal nutrition (pp. 147-167). Addis Ababa: IFPRI.

Khalid, H., Gill, S., \& Fox, A. M. (2019). Global aid for nutritionspecific and nutrition-sensitive interventions and proportion of stunted children across low- and middle-income countries: does 
aid matter? Health Policy and Planning, 34(Supplement_2), ii18ii27. https://doi.org/10.1093/heapol/czz106

Laar, A., Aryeetey, R., Akparibo, R., Zotor, F., Academic, G. S. U. N., \& Platform. . (2015). Nutrition Sensitivity of the of the 2014 budget statement of Republic of Ghana. The Proceedings of the Nutrition Society. https://doi.org/10.1017/S0029665115002426

Management Technologies Consutants. (2013). A Baseline Rapid Appraisal of Civil Society Organizations Involvement in Nutrition Actions and Advocacy. Retrieved from Accra, Ghana:

McGovern, M. E., Krishna, A., Aguayo, V. M., \& Subramanian, S. V. (2017). A review of the evidence linking child stunting to economic outcomes. International Journal of Epidemiology, 46(4), 1171-1191. https://doi.org/10.1093/ije/dyx017

Mills, C. A. (2018). Politics, policy, and implementation: The 'Ghanaian Paradox'. Brookings Institution Retrieved from https://www. brookings.edu/blog/africa-in-focus/2018/07/18/politics-policyand-implementation-the-ghanaian-paradox/

Ministry of Food and Agriculture (MoFA). (2007). Food and Agriculture Sector Development Policy (FASDEP II). Accra, Ghana: MoFA Retrieved from http://mofa.gov.gh/site/wp-content/uploads/ 2011/06/FASDEP-II-FINAL1.pdf

Ministry of Food and Agriculture (MoFA). (2010). Medium Term Agricultural Sector Investment Plan (METASIP): 2011-2015. Accra, Ghana: MoFA

Ministry of Gender, C. a. S. P. M. (2020). Livelihood Empowerment Against Poverty (LEAP). Accra: MGCSP Retrieved from http:// mogcsp.gov.gh/index.php/projects/livelyhood-empowermentagainst-poverty-leap/

Ministry of Health (MoH). (2007a). Child Health Strategy. Accra, Ghana: $\mathrm{MoH}$

Ministry of Health (MoH). (2007b). Under 5 Child Health Strategy: 2007-2015. Accra, Ghana: MOH

Ministry of Health (MoH). (2007c). Under Five's Child Health Policy: 2007-2015. Accra, Ghana: $\mathrm{MoH}$

Ministry of Health (MoH). (2014). The Health Sector Monitoring and Evaluation Framework. Accra: $\mathrm{MoH}$

National Development Planning Commission (NDPC). (2016). The Cost of Hunger in Africa (Ghana): Social and Economic Impact of Child Undernutrition. Accra: NDPC

Nisbett, N., \& Barnett, I. (2017). Explaining the reduction in child undernutrition in the Indian state of Maharashtra between 2006 and 2012: An analysis of the policy processes. Food Policy, 70, 27-39. https://doi.org/10.1016/j.foodpol.2017.05.006

Nwafor, M. (2018). Review of Nutrition Policy Environment and Implementation Effectiveness in Ghana. Accra

Nyumuah, R. O., Hoang, T. C., Amoaful, E. F., Agble, R., Meyer, M., Wirth, J. P., \& Panagides, D. (2012). Implementing large-scale food fortification in Ghana: Lessons learned. Food and Nutrition Bulletin, 33(4 Suppl), S293-300. https://doi.org/10.1177/15648265120334s305

Picanyol, C., Horton, S., Chautala, A., Connolly, H., Fracassi, P., François, J., Zagre, N. M. (2015). Tracking investments in nutrition in Africa: experience from four countries. Oxford, UK: Oxford Policy Management Ltd Retrieved from https://www.opml.co.uk/files/Publications/ corporate-publications/working-papers/wp-tracking-investments-innutrition-in-africa.pdf?noredirect $=1$

Pinto, R. F. (2011). The Nutrition Area in Ghana Institutional Assessment. Retrieved from Accra, Ghana

Pittore, K., \& Aryeetey, R. (2016). Business and its Role in Improving Nutrition: Opportunities, Challenges and Solutions for Ghana. Case Studies and Key Messages from the Workshop. Retrieved from England.

Scaling Up Nutrition Movement (SUN). (2014). SUN Countries: Ghana.
Scaling Up Nutrition Movement Secretariat (SUN). (2015). Gospel musician from Ghana launches new album and the First 1,000 day's campaign. Retrieved from https://scalingupnutrition.org/ news/gospel-musician-from-ghana-launches-new-album-andthe-first-1000-days-campaign/

Schiffer, E., \& Hauck, J. (2010). Net-Map: Collecting Social Network Data and Facilitating Network Learning through Participatory Influence Network Mapping. Filed Methods, 22(3), 231249.https://doi.org/10.1177/1525822X10374798

Schiffer, E., \& Waale, D. (2008). Tracing power and influence in networks: Net-map as a tool for research and strategic network planning. International Food Policy Research Institute.

Service, G. S. (2013). 2010 Population and housing census. Accra: Ghana Statistical Service.

Smith Fawzi, M. C., Andrews, K. G., Fink, G., Danaei, G., McCoy, D. C., Sudfeld, C. R., \& Fawzi, W. W. (2019). Lifetime economic impact of the burden of childhood stunting attributable to maternal psychosocial risk factors in 137 low/middle-income countries. BMJ Global Health, 4(1), e001144. https://doi.org/10. 1136/bmjgh-2018-001144

Sodjinou, R., Bosu, W. K., Fanou, N., Deart, L., Kupka, R., Tchibindat, F., \& Baker, S. (2014a). A systematic assessment of the current capacity to act in nutrition in West Africa: Cross-country similarities and differences. Global Health Action, 7, 24763. https://doi. org/10.3402/gha.v7.24763

Sodjinou, R., Fanou, N., Deart, L., Tchibindat, F., Baker, S., Bosu, W., \& Delisle, H. (2014b). Region-wide assessment of the capacity for human nutrition training in West Africa: Current situation, challenges, and way forward. Global Health Action, 7, 23247. https://doi.org/10.3402/gha.v7.23247

Strengthening Partnerships Results and Innovations in Nutrition Globally (SPRING)., \& Ghana Health Service (GHS). (2016). Ghana: Landscape Analysis of Anemia and Anemia Programming. Arlington, VA: Strengthening Partnerships, Results, and Innovations in Nutrition Globally (SPRING)

Sunguya, B. F., Poudel, K. C., Mlunde, L. B., Urassa, D. P., Yasuoka, J., \& Jimba, M. (2013). Nutrition training improves health workers' nutrition knowledge and competence to manage child undernutrition: A systematic review. Frontiers in Public Health, 1, 37. https://doi.org/10.3389/fpubh.2013.00037

te Lintelo, D. J. H., Page, P., Kaganda, J., \& Esau, D. (2020). Tanzania's story of change in nutrition: Political commitment, innovation and shrinking political space. Global Food Security, 24, 100350. https://doi.org/10.1016/j.gfs.2020.100350

UN 'Renewed Efforts against Child Hunger and Undernutrition' (REACH). (2014). Nutrition Governance for Multi-sector Approaches in Ghana: Capacity Assessment \& Development Response. Retrieved from Accra, Ghana:

UNICEF. (2012). CNN and UNICEF raise awareness of the silent emergency of child stunting. Retrieved from https://www. unicef.org/nutrition/index_66188.html

United Nations Children's Fund. (1998). State of the the Worlds Children 1998: Focus on Nutrition. UNICEF.

United states Agency for International Aid (USAID). (2020). Living the Goodlife in Ghana. USAID Retrieved from https://www. thecompassforsbc.org/sbcc-spotlights/living-goodlife-ghana\# main-content

World Health Organization (WHO). (2014). Global Nutrition Targets 2025. (WHO/NMH/NHD/14.2). Geveva: WHO Retrieved from https://apps.who.int/iris/bitstream/handle/10665/149018/WHO_ NMH_NHD_14.2_eng.pdf?ua=1 


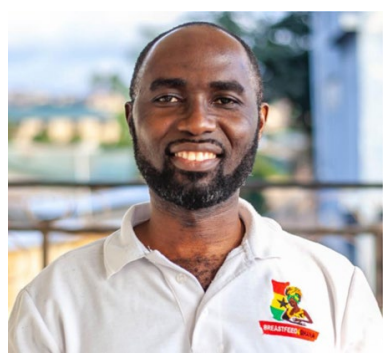

Richmond Aryeetey Is an Associate Professor at the University of Ghana. Richmond is leading the Ghana Stories of Change in Nutrition work for Transform Nutrition West Africa and has worked in Ghana as a researcher in maternal and child health for the last 13 years. His expertise spans Primary research skills, formative research, and Monitoring and Evaluation,

Training and Facilitation. Richmond's current research projects include studies on food environment of urban-dwelling adolescents, and exploring policy options for scaling up optimal feeding among infants and young children in Ghana.

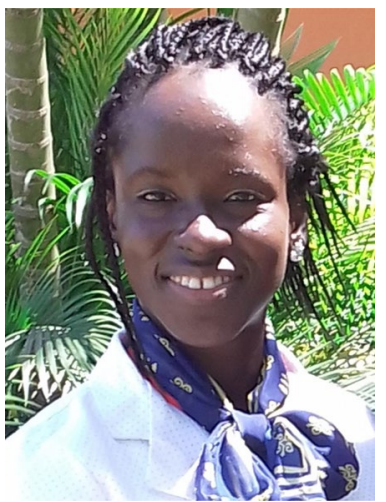

Afua Atuobi-Yeboah Is a Ph.D. candidate at the School of Public Health, University of Ghana, Legon. Afua is a Canadian Queen Elizabeth II Diamond Jubilee (2020-2021). She was a Fellow of the African Women in Agricultural Research and Development (AWARD) 2015-2016 and an alumnus of the African Nutrition Leadership Programme (ANLP), North-West University. Her research has focused on nutrition interventions aimed at improving nutrition, health and overall livelihoods of rural women and their households particularly children and adolescents in Ghana.

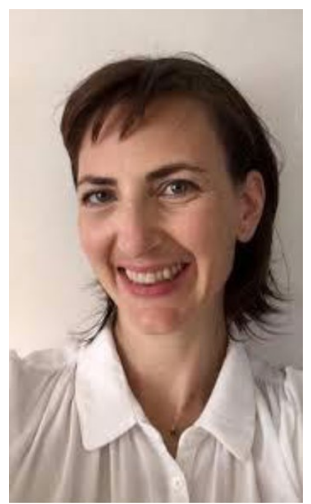

Lucy Billings Is the project manager for Transform Nutrition West Africa, coordinating across the project workstreams and between the project partners. She holds a M.S. and M.P.H. from Tufts University where she studied food and agriculture policy. Lucy was a Leland International Hunger Fellow from 2011-2013. She has worked with IFPRI for seven years providing technical support and coordination for research on food security, poverty reduction, and nutrition in developing countries.

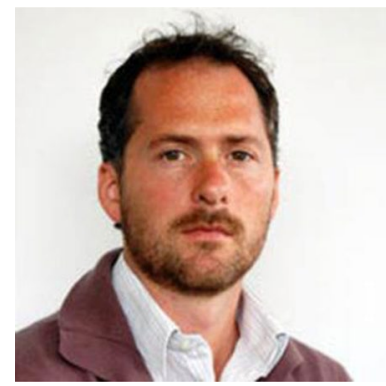

Nicholas Nisbett Is a Senior Research Fellow at the Institute of Development studies, UK. Nickleads on the Evidence and diagnostics short course for Transform Nutrition West Africa and co-leads the Stories of Change in Nutrition work. He alsoco-leads the Health and Nutrition Cluster of researchers and teaches on development and nutrition at the Institute of Development Studies. His workexplores the political economy of nutrition policy and programming in South Asia and Sub-Saharan Africa and he has published research on national and international nutrition governance and policy processes, community level drivers of nutrition and community accountability. He has led major multi-methods evaluations of nutrition and livelihoods programmes as well as research focused on state, district and local level constraints to implementation of programmes at scale.

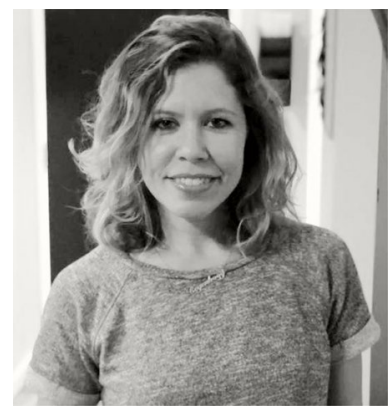

Mara Van den Bold Is a Senior Research Analyst at the International Food Policy Research Institute, Washington, DC. Maracoordinates the Stories of Change work for Transform Nutrition West Africa. At IFPRI, her work has primarily fallen under several large research consortia, including Transform Nutrition (2012 2017), Leveraging Agriculture for Nutrition in South Asia (LANSA) (2012 - 2018), and Transform Nutrition - West Africa (TN-WA) (2017 Enhanced Homestead Food Production program in Burkina Faso.

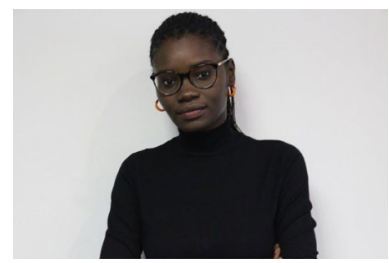

Mariama Toure Is a Research Analyst at IFPRI West and Central Africa Office. Mariama is involved in the Evidence Synthesis and the Stories of Change components of the project. Her work focuses on identifying gaps in maternal, infant, and young child nutrition data in West Africa, rapid reviews, quantitative analyses for nutritional change stories. Mariama also contributes to Transform Nutrition West Africa's newsletter to inform on the latest publications on nutrition in the region. As a research analyst at IFPRI, she also works on various projects in the Poverty, Health and Nutrition Division (PHND). Mariama holds master's degrees in Statistics and in Public Economics, with a specialization in Health Economics. 